\title{
VARIOUS MODIFICATIONS OF THERMOPILES HAVING A CONTINUOUS ABSORBING SURFACE
}

\author{
By W. W. Coblentz
}

\section{CONTENTS}

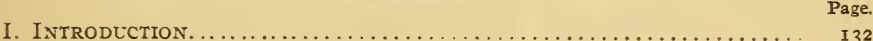

II. TheORETICAL DEDUCTIONS OF EFFICIENCY OF THERMOPILES ........ I33

III. Method of Construction . . . . . . . . . . .

Receivers with thermal elements in series-parallel........... I ${ }^{8}$

IV. EXPERIMENTAL TESTS OF RADIATION SENSITIVITY OF THERMOPILES... I42

The radiation sensitivity as a function of the area exposed..... $\mathrm{I4}_{4} 2$

The radiation sensitivity as a function of thermal conductivity and of emissivity............................. I44

Relation between external and internal resistance of a thermopile. I45

Thermoelectric power of bismuth-silver. . . . . . . . . $4 . \ldots \ldots$ I 8

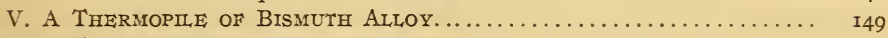

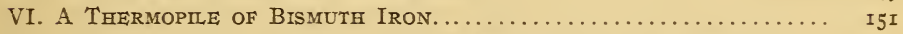

VII. A RADIOMETER ATTACHMENT FOR MONOCHROMATIC ILLUMINATORS.... I54

VIII. A ThERMOPILE FOR ABSOLUTE MEASUREMENTS OF RAdIATION...... I57

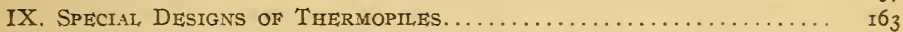

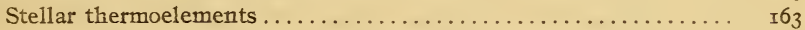

An absolute thermopile for the measurement of nocturnal radiation. . I $\mathrm{I}_{5}$

A thermopile for physiological problems................ I67

The thermopile as a photometer . .................. I68

A thermoelement with a concentrating mirror.............. I69

Miscellaneous designs. ......................... I69

X. SPECIFICATION OF THE Radiation SENSITIVITY OF A THERMOPILE OR

BOLOMETER. . . . . . . . . . .

XI. Summary. . . . . . . . . . .

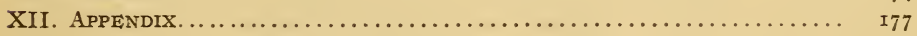

Note $1 .-$ Galvanometer mirrors. ..................... I77

Note $2 .-$ Vacuum galvanometers. ...................... I 77

Note 3.-The most efficient combination of thermopile and galvanometer resistance...................... I80

Note 4. -Test of stellar thermoelements on stars............ I8z

Note 5.-The maintenance of high vacua by means of metallic

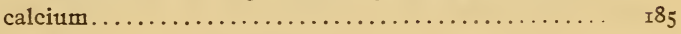




\section{INTRODUCTION}

The linear thermopile, consisting of bismuth and silver wires, with rectangular receivers attached to the junctures of these two metals was constructed about three years ago. ${ }^{1}$

Its novelty consists in a series of overlapping receivers, forming a continuous surface which has all the advantages of a good bolometer, with none of the disadvantages of that well-known instrument. At first the wide application of this device could not be foreseen. In fact, the first instrument was constructed in part to refute the prediction that such a design (proposed about a year earlier) was doomed to failure because of lack of insulation. As an illustration of some of the contradictions in mechanical construction it is relevant to say that there is no difficulty in obtaining good insulation, and that one is chiefly concerned in obtaining good metallic contact of the fine wires used in this device.

The object of the present paper is to illustrate various modifications and uses to which this instrument has been adapted, and to indicate further applications.

The wide range of usefulness of this radiometer is owing to the fact that its heat capacity is sufficiently low so that it attains a maximum temperature in less than four seconds (and 92 per cent of its maximum in two seconds); and yet the receiver is sufficiently massive so that it may be operated in the open without being disturbed by the cooling effect of air currents. No doubt the thinnest bolometer material would be more sensitive than the thermopile, when used in a high vacuum, but in that case the general applicability of these two types of instruments is not being considered.

The general utility of the thermopile as a radiometer will be apparent from the various modifications which will be described presently. It will be sufficient to note briefly that the investigation of the effect of radiant energy upon matter, and in passing through matter, and the investigation of the laws governing the passing of energy by radiation from matter, occupies the attention of many of the foremost experimenters. The visible and ultraviolet radiations are being used as stimuli by chemists for producing photochemical reactions, by biologists and physiologists 
in their investigations of the effect of radiant energy upon lower organisms, by psychologists in their studies of the effect of light upon the eye, and by physicists in their investigations of photoelectric and other phenomena. In all such investigations it is desirable to know the energy value (mechanical equivalent) of the different radiations (wave lengths) used as stimuli. For this purpose it is necessary to use a radiometer which functions independently of the frequency of the stimulus. Many of the aforementioned groups of investigators lack experience in operating a bolometer and have not the time available to acquire such experience even if their laboratories are fortunately so situated as to permit of the use of a bolometer. It is with the needs chiefly of this type of investigators in mind, that the various thermopile experiments herein described have been made.

As mentioned in the first paper ${ }^{2}$ the selection of silver to complete the element with bismuth was because of the ease with which it can be cleaned (in order to obtain complete contact in soldering the metals) and annealed, which are the prime requisites in construction. It will be shown presently that neatness of construction is of more importance than a high thermal emf in order to produce a thermopile having a high radiation sensitivity.

The present form of bismuth-silver thermopile is the result of experiments upon materials that are sufficiently strong so as to withstand rough usage. In addition to this feature, it has a high sensitivity and a quick action. It is the outcome of an attempt to produce a receiver, having a completely opaque surface (i. e., no open spaces in it), which may be calibrated and used (in air) in making absolute measurements of radiant energy.

\section{THEORETICAL DEDUCTIONS OF EFFICIENCY OF THERMOPILES}

In connection with the question of the possibility of replacing the dynamo by a thermoelectric generator, Rayleigh ${ }^{3}$ has discussed the thermodynamic efficiency of the thermopile. In his computations only the specific resistances and the thermal conductivities of the materials were considered, the loss by radiation being negligible. He showed that the useful work done externally attains a maximum when the external resistance equals the inter- 
nal resistance. He compared the mathematical expression for the external work with the energy dissipated by heat conduction in the elements. The ratio of these two quantities is the efficiency. He found that the efficiency of the thermopile does not depend upon the absolute dimensions (cross sections) of the elements, or of their thermal and electrical resistances, but only upon the ratios of these quantities. The efficiency of the thermopile is independent of the number and lengths of the elements, and of the temperature difference of the junctions; it is dependent only upon the thermoelectric power of the single elements. The conclusion arrived at was that a thermopile would be far less efficient than a dynamo and steam engine. Kollert ${ }^{4}$ also found that the efficiency of the thermoelectric generator does not depend upon the number or dimensions of the elements. In the generators tested by him the source of heat was a series of bunsen burners. He found the efficiency of the various types of thermoelectric generators to be from 5 to 12 per cent.

Hoffmann ${ }^{5}$ investigated experimentally the effect of the loss of heat by radiation and by conduction upon the efficiency of the thermopile. He arrived at practically the same conclusions as did his predecessors.

An important contribution to the discussion of the efficiency of thermopiles is by Altenkirch. ${ }^{6}$ He neglects the Thomson effect for small temperature differences and sets the thermal emf proportional to the temperature difference. He found that (I) the efficiency is independent of the number of junctions, (2) the most favorable conditions are obtained when the ratio of the electrical resistance to the heat conductivity is the same in both wires, (3) for small emfs the electrical energy developed increases as the square of the emf, but for large ${ }^{7}$ emfs the Peltier effect must be considered. (4) The external resistance may be two or three times the internal resistance without seriously affecting the maximum efficiency of the thermopile. The last deduction is of interest in view of the generally accepted notion that it is very essen-

\footnotetext{
${ }^{4}$ Kollert: Elektro-Tech. Zs., 11, p. 333; 1890.

${ }^{5}$ Hoffmann: Inaug. Diss. Rostock; 1898.

'Altenkirch: Phys. Zs., 10, p. 560 ; 1909.

${ }^{7}$ It will be shown on a subsequent page that the increase in radiation sensitivity is far from being proportional to the increase in emf., when a comparison is made of a bismuth-silver and a bismuth-iron thermopile.
} 
tial to have an exact equality of internal and external resistance. He gives a series of curves showing the efficiency of the thermopile for different values of thermoelectric power, and for different values of external resistance. These efficiency curves are very flat at the maximum and they are far less symmetrical than the herein-described observations, which show that the radiation sensitivity of the thermopile is the same when the (external) galvanometer resistance is one-half, or twice the resistance of the thermopile.

The aforementioned discussions relate to thermopiles which are to be used as thermoelectric generators to replace the dynamo. The most recent theoretical contribution on the construction of thermopiles for measuring radiant energy, and relating especially to vacuum thermopiles, is by Johansen. ${ }^{8}$ His assumptions and conclusions do not differ radically from those of his predecessors. His deductions are that (I) the galvanometer resistance should be equal to the resistance of the thermoelements; (2) the radii of the two wires of the thermoelement should be so chosen that the ratio between the heat conductivity and the electrical resistance is the same in both; (3) the heat loss by conduction through the wires must equal the heat loss by radiation from the junctions (a question that can be answered only by direct experiment with the material to be used); and (4) the radiation sensitivity is pro= portional to the square root of the exposed surface. In his experimental instrument, the "cold" (unexposed) junctions are joined directly to the binding posts. This is likely to cause a "drift" of the zero reading owing to the fact that the air is warmed by the incident radiation and the "cold" junction can not quickly assume the temperature of the surrounding air. In a subsequent paper $^{9}$ he recognizes this defect, and gives a symmetrical design with circular receivers as obtained in the Rubens thermopile.

He makes further computations showing that in the unsymmetrical type of thermopile the radiation sensitivity is $\sqrt{2}$ times that of the symmetrical design. In other words, his unsymmetrical design should be about 40 per cent more sensitive than the Rubens thermopile and the herein-described thermopiles. 
Johansen states that using an iron-constantan element the Peltier effect decreases the deflections by $1 / 4$ per cent and is of no consequence so long as the same resistance is in the circuit. In an iron-bismuth element the Peltier effect is four times as large, i. e., one can observe with an accuracy of I per cent when the external resistance is varied. This estimate is in agreement with previous computations ${ }^{10}$ which indicated a correction of about I part in 300 for iron-constantan. On the same basis of computation an error of about I part in I 50 would result in the galvanometer deflections when using bismuth and silver for the thermal element. However, the amount of current flowing may be controlled by placing sufficient resistance in series to reduce all the galvanometer deflections to the same value. In this manner the Peltier effect will be the same for all intensities of the incoming radiation. By using a rotating sector to reduce the intensities of the radiations so as to produce approximately the same deflections, the relative values of the radiations will not be in error.

\section{METHOD OF CONSTRUCTION}

The method of construction of the thermoelements remain practically the same as previously described. ${ }^{11}$ Silver wire is used with the bismuth because of its low resistance and because it is easily cleaned and annealed by heating it on a thin metal plate in a bunsen flame. Its weak point (which seems to be a common property of fine wires, e. $\mathrm{g}$., $\mathrm{Cu}, \mathrm{Cd}$, etc.) is deterioration by the action of sulphides in the air. It is therefore given a thin coat of shellac, after mounting the elements and determining their resistance. The shellac becomes thoroughly baked upon the silver wires during the process of smoking the receivers over a sperm candle. This shellac does not affect, by a measurable amount, the sensitivity or heat capacity (hence quickness of action) of the thermopile. This was amply demonstrated by testing the sensitivity of a thermopile before and after shellacking the wires. Several thermopiles were constructed of bismuth and copper wires. The main obstacle experienced in construction was the difficulty in soldering the copper wires in case they became tar-

10 This Bulletin, 4, p. 402; 1907. ${ }_{11}$ This Bulletin, 9, p. 7, 1912; J. Franklin Inst., 172. p. 559, I911. 
nished. The sensitivity was as high as that of the bismuth-silver thermopile.

The method of joining the bismuth and the silver wires by means of the V-shaped, electrically heated, nichrome wire is continued as described in the previous paper. No difficulty is experienced in handling silver or copper after annealing. The best results are obtained by attaching a bead of tin about $0.05 \mathrm{~mm}$ diameter on the end of the silver (or copper) wire. The simplest procedure is to cut the wires the proper length ( $\mathrm{Bi}, 3.5 \mathrm{~mm} ; \mathrm{Ag}$, Io to $12 \mathrm{~mm}$ ). All the subsequent operations are performed upon a pad of clean white paper. A reading glass is used to magnify the objects. First the beads of tin are attached to the silver wires and trimmed to the proper size. The silver wire is then held secure by covering nearly the whole length of it with a small metal weight (say, a block of brass 4 by 5 by $15 \mathrm{~mm}$ ), the bead of tin protruding. By means of a light, flexible, fine-pointed tweezers one end of the short bismuth wire is held in contact with the bead of tin and the two are melted together by touching the silver wire, close to the bead, with the nichrome heater. This silver wire, with the bismuth wire attached thereto, is then seized with the tweezers and the free end of the bismuth wire is melted to another silver wire. An appreciable tensile stress is then applied to determine whether the juncture is strong. The actual amount of tension is learned by experience; usually the juncture, which is an alloy of bismuth and tin, is stronger than the bismuth wire. These elements are then held secure by means of the brass weight already mentioned. The rectangular receiver is pushed under the juncture and is melted thereto by touching it lightly with the nichrome heater. These tin receivers are best handled by means of wooden toothpicks which are cut flat and pliable at one end, and moistened to hold the metal plate in transferring it. A speck of rosin placed on the receiver causes the bismuth to fuse to the tin over the gireater part of its length. This warms the wire near the juncture thus compensating somewhat for the heat lost by conduction along the wire, and it seems to increase the radiation sensitivity. That the heat loss by conduction along the wire is appreciable is shown by exposing 0.5 to $\mathrm{I} \mathrm{mm}$ length of the bismuth wire which extends beyond the edge of the receiver. Using a 
black background to prevent reflection of radiation from the rear, upon the thermopile, the sensitivity is higher than when only the receiver is exposed. This demonstrates also that the bismuth wires are sufficiently long so that the cold junctions are not appreciably heated by conduction from the exposed junctions. When the slit is considerably narrower than the receiver the sensitivity is somewhat reduced, owing to the fact that the whole receiver is losing heat by convection and by radiation, while only part of the receiver is receiving heat. Hence it is desirable to design the width of the receiver for the problem under investigation.

In the first thermopiles constructed the entire rear surface of the receivers was given a thin coating of shellac. As experience was gained it was found that putting shellac on the overlapping edge of the receiver was sufficient for insulation. After mounting them, the central line of receivers was caused to adhere by moistening the shellac with alcohol. The insulation tests were made before and after a series of receivers were in contact. In this form of linear thermopile, having bismuth wire o.I $\mathrm{mm}$ diameter, silver wire $0.036 \mathrm{~mm}$ diameter, and receivers of tin $0.02 \mathrm{~mm}$ in thickness (this sheet tin is obtained from the ordinary "paper" condensers used in telephone service), the time required for the galvanometer to register a maximum deflection was about twice the time of single swing of the galvanometer, i. e., using a 3 -second single swing on open circuit, the maximum galvanometer deflection was attained in 5.5 to 6 seconds after exposing the thermopile to radiation.

As shown in Figs. $x$ and 3 the ends of each thermoelement are soldered to small $(0.5 \mathrm{~mm})$ copper binding posts. This enables one to test the resistance ( $0.4 \mathrm{I}$ to 0.45 ohms for bismuth $0.1 \mathrm{~mm}$ in diameter) of each thermoelement, and renders it convenient to replace defective or broken elements.

Receivers with thermal elements in series-parallel.-As the construction of thermopiles progressed it was found that, provided there were sufficient thermoelements per unit area of receiver so that there was no lag in equalizing the temperature over the whole absorbing surface, there was no appreciable gain in sensitivity by increasing the number of thermoelements within a given area of receiver. This is owing to the fact that there is an optimum size 
of receiver which absorbs at a sufficient rate to compensate for the losses by radiation from the surface and by conduction along the wires. Using bismuth wire $0.06 \mathrm{~mm}$ diameter there is but little gain in placing more than 2 junctures per $\mathrm{I} \mathrm{mm}$ length of receiver;
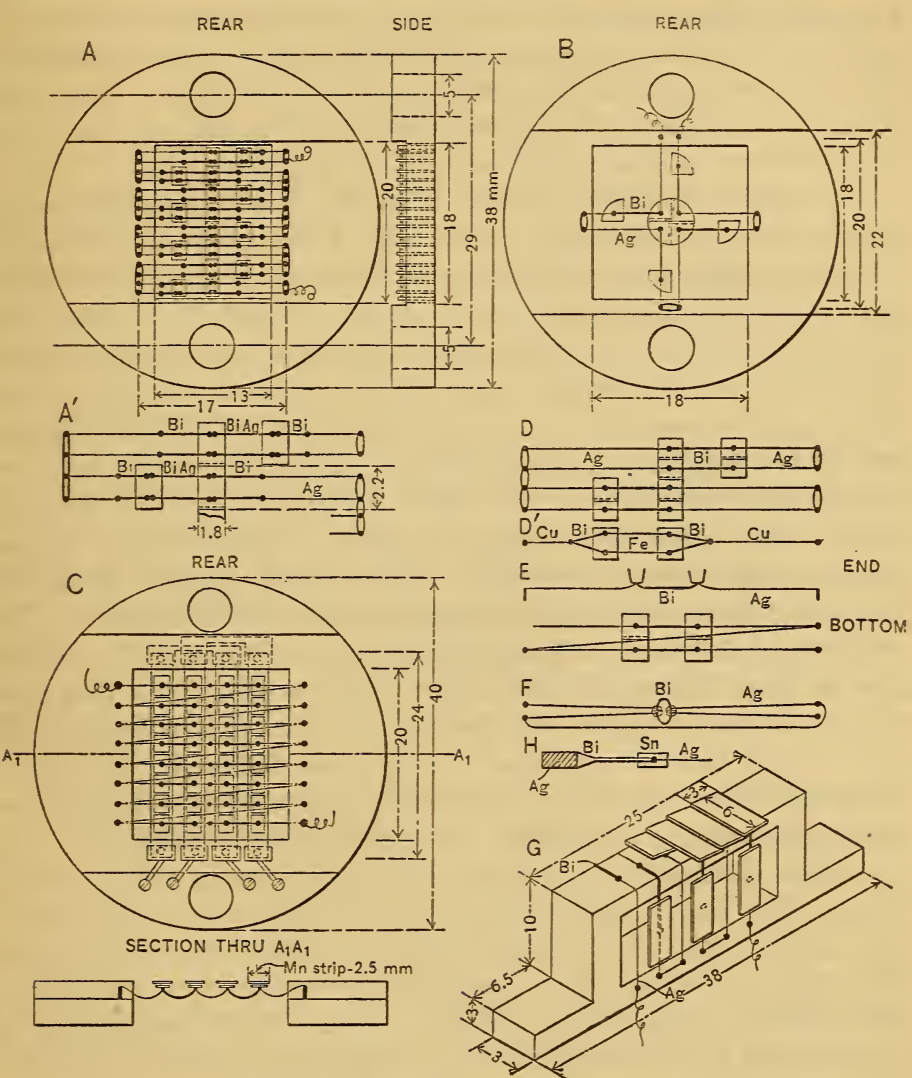

FIG. I.-Various designs of thermopiles

and there is a decided loss in sensitivity by using only I juncture per I.2 mm length. On the other hand, using bismuth wire 0.1 $\mathrm{mm}$ in diameter there was no gain in placing more than 2 junctures per I mm length of receiver; and there was no appreciable loss in 
sensitivity by having as few as I juncture per $\mathrm{r} .5 \mathrm{~mm}$ length of receiver. The next step was to further shorten the time to attain a maximum deflection and to reduce the internal resistance. By attaching two thermoelements to one receiver as shown in Fig. IA, and in illustration No. I of Fig. 3, the number of overlapping receivers is reduced by one-half. This reduces the superfluous metal at the lap, and also the amount of insulation. The time required to attain a maximum deflection was reduced from 2 to I. 3 times that of the single swing of the galvanometer.

The dilute alcoholic solution of shellac used for insulation is applied to the overlapping edge with a fine-pointed toothpick. It is also applied to the silver wire on the receiver, and after mounting, the whole silver wire is covered with shellac. The front side is given a thin coat of a mixture of lampblack and platinum black in alcohol, with sufficient turpentine to make it adhesive. The finest grained material is applied, the coarsest material having settled to the bottom of the container. The thickness of the layer is just sufficient to cover the bright metal as viewed in the sunlight. This blackened surface is then smoked over a sperm candle as previously described. Usually the shellac, from the insulating joints, melts and makes a smooth black surface. The smoking is therefore continued until this is obliterated. All the soot is then brushed off with a fine-haired brush, and a thin coat of soot is again applied. If this becomes dusty, it is brushed off and the surface is resmoked. The paint below it, of course, remains intact. In all the thermopiles discussed in this paper the receiving surfaces were smoked in the manner just described, the final thin coating of soot being deposited from a rather smoky flame. The fine-grained "hard" bluish smoke from the flame is not used because it is grayish and has a higher reflecting power. The radiation sensitivity is surprisingly constant on resmoking. The smoke is produced by holding a sheet-iron funnel (about ro $\mathrm{cm}$ long and $5 \mathrm{~cm}$ in diameter at the base with a slit 2 by $10 \mathrm{~mm}$ at the top) over a sperm candle.

By joining two elements in series-parallel the internal resistance is reduced to one-fourth that which would obtain in thermopile having all the elements in series. The emf is reduced by one-half, but, as will be shown presently, the radiation sensitivity is unaffected. In case one uses a potentiometer or a moving coil gal- 
vanometer, it is of course desirable to use a great many elements in series in order to attain a high emf.

In the series-parallel form of thermopile the radiation sensitivity was increased ro to 12 per cent over the average sensitivity of the previous design. Using a galvanometer single swing of 3 seconds the maximum deflection is attained in 3.8 to 4 seconds and 92 to 95 per cent of the maximum deflection is attained in 2 seconds. The zero reading is very constant in both forms of thermopiles. Frequently the cause of zero shift is to be located in the warming of the jaws of the slit (or of the window, if any be used) by the incident radiation. The jaws of the slit should therefore be of metal and they should be sufficiently massive to prevent an appreciable rise in temperature. In some of his most sensitive spectral thermopiles the writer uses a double-walled slit. The outer one is made of thin sheet copper which is cut to fit the curvature of the spectral lines.

In the series-parallel arrangement the two elements are fused to the receiver in the same manner as was described for attaching the single elements. The silver wires are attached to the copper posts (previously covered with solder) by means of Wood's alloy, which is used freely to connect the four posts as shown in Fig. IA. The silver wires are sufficiently long to cross the four posts. They must be untarnished, otherwise the Wood's alloy does not make good contact and an extra resistance, of 0.1 ohm or greater, is introduced.

With reference to the reflecting power of the lampblack paint and the superficial layer of soot it may be added that such a surface is nonselective (i. e., it has no narrow absorption bands) and practically uniformly absorbing throughout the spectrum. ${ }^{12}$ In the surface thermopiles previously described ${ }^{13}$ no receivers were attached to the unexposed junctions, and no provision was made for air circulation near them. In Fig. $\mathrm{IG}$ is shown a design which embodies these improvements. It is important to have the exposed and the unexpered junctions symmetrical in size and in emissivity so that they will come to the temperature of the surrounding air (which is warmed by the incident radiation) at a uniform rate and thus avoid drifting of the zero reading of the galvanometer. 


\section{EXPERIMENTAL TESTS OF RADIATION SENSITIVITY OF THERMO- PILES}

Under this heading are collected the most important and the most crucial experimental tests relating to the various factors which affect the sensitivity of thermopiles which were fully completed, mounted, and ready for use. In the preceding paper ${ }^{14}$ some of the tests were made on single thermocouples and the results attained were not always consistent with those observed on completed instruments. This was to be expected, for in assembling the single thermocouples into a complete instrument, the emissivity was changed.

The radiation sensitivity as a function of the area exposed.-In the single thermocouples the tests showed that the sensitivity was not proportional to the square root of the area exposed to radiation, but that the area had an optimum value which gave a considerably higher sensitivity than required by the square-root law. From this it appears that the highest sensitivity is attained by building up a composite receiver of elements having individual receivers of a size giving the optimum sensitivity. Just how much greater this sensitivity will be than that attainable by using a less favorable size of receiver is undetermined. From the data previously published the expected gain may amount to 50 per cent. The estimates of increased sensitivity given in the preliminary publications ${ }^{15}$ are evidently too high. It was there stated that a receiver $4 \mathrm{~mm}$ in length built up of 4 individual receivers, $\mathrm{I}$ by $\mathrm{I} \mathrm{mm}$ in area, would be twice as sensitive as a single receiver 4 by $\mathrm{I} \mathrm{mm}$ in area. The sensitivity of a receiver composed of 4 parts, I by $\mathrm{I} \mathrm{mm}$ in area, is not four times that of one of its components, I by I $\mathrm{mm}$ in area. It is only twice (square root of the total area exposed) that of the unit area, as is well illustrated on a subsequent page (see Fig. 6). In the case of the single receiver $4 \mathrm{~mm}$ in length, as compared with the composite receiver of 4 elements $\mathrm{I} \mathrm{mm}$ in length, the gain in sensitivity in the latter is the part contributed by the small receivers being of a size which gives an optimum sensitivity as compared with the $4 \mathrm{~mm}$ length which falls below the square-root law in sensitivity. This optimum size

14 This Bulletin, 9, p. 7, 1912; Phys. Zs. Zeit., 14, p. $68_{3}$, 1913.

${ }_{15} \mathrm{~J}$. Franklin Inst., 175, p. 49\%, 1913; Zs. Instrumentenkïnde, 34, p. $1_{4}$, $19 \mathrm{r}_{4}$ 
of receiver arises from the fact that a minimum area of receiver is required which absorbs radiant energy at a sufficiently rapid rate to compensate for the loss of heat by conduction along the wires. On the other hand if the receiver is large the loss by radiation from the receiver is more important than that of conduction along the wire (and there is also a lag in attaining thermal equilibrium in the receiver) owing to the lag in heat conduction from the remote edges which are at the highest temperature. Using bismuth wire o.I $\mathrm{mm}$ in diameter the minimum area of the receiver giving the highest sensitivity is of the order of $\mathrm{I} \mathrm{mm}^{2}$.

In the thermopiles first constructed I thermoelement. was placed per I $\mathrm{mm}$ length of the completed receiver. This number was increased to 2 elements (several thermopiles ${ }^{16}$ had 22 elements in ro $\mathrm{mm}$ length of completed receiver), and while fortunately the sensitivity was not decreased, it was usually not very markedly increased (owing to the extra insulation and heat capacity) as compared with the thermopile having a smaller number of elements. On the other hand it was found that when there was but one element per $1.5 \mathrm{~mm}$ length of the finished receiver, the time for attaining a maximum deflection was increased owing to the slowness of heat conduction from the extreme edge and the consequent delay in attaining temperature equilibrium in the receiver. In the thermopiles constructed of bismuth wire $0.1 \mathrm{~mm}$ in diameter and silver wire $0.036 \mathrm{~mm}$ in diameter it was found that the the radiation sensitivity was practically the same for one thermoelement per 0.8 to $1.2 \mathrm{~mm}$ length of the completed receiver. The usual width of the individual receivers was 1.5 to $1.8 \mathrm{~mm}$ and the length was I.O to I.I mm. In thermopiles constructed of bismuth wire $0.06 \mathrm{~mm}$ and silver wire $0.03 \mathrm{~mm}$ in diameter, this tolerance was not so large, the best length of the individual receiver being of the order of $0.5 \mathrm{~mm}$ to $0.8 \mathrm{~mm}$. In the thermopiles having all the elements in series the time required for attaining a maximum deflection was about twice the time of single swing of the galvanometer. This was found true for a galvanometer. swing of 2.5 to 5 , seconds. In the new design Fig. IA, in which two elements are joined in series-parallel, less shellac is required

\footnotetext{
${ }_{16}$ This Bulletin, 9 , p. $283, x_{13}$. This thermopile No. 6 , having a resistance of ro. 8 ohms, had a receiving
} surface $5 \mathrm{~mm}$ wide, no receivers were used on the unexposed junctions. 
for insulation, there is less inactive metal in the lapping of the adjacent receivers, and the time required to attain a maximum deflection is reduced to less than four-thirds the time of single swing of the galvanometer. The receivers are 1.5 to $1.8 \mathrm{~mm}$ wide and $2.2 \mathrm{~mm}$ long; and the radiation sensitivity is the highest yet attained.

The radiation sensitivity as a function of thermal conductivity and of emissivity.-It is of interest to cite the behavior of several thermopiles to illustrate the marked effect in sensitivity that may be experienced by deviating from the general method of construction. For example, the central line of receivers of one thermopile (No. I0; 22 junctions of bismuth wire $0.06 \mathrm{~mm}$ and silver wire $0.03 \mathrm{~mm}$; resistance 22 ohms; receivers 0.9 by 1.5 ; area exposed $\mathrm{r} .5$ by $10 \mathrm{~mm}$ ) was given an additional coating of shellac to cause the individual receivers to adhere, instead of resorting to the usual method of moistening the insulating layer of shellac with alcohol. The instrument was slow in response to a radiation stimulus, and it was insensitive. This extra shellac was then removed (by means of blotting paper wet with alcohol) and on resmoking it the radiation sensitivity was increased by 48 to 50 per cent. It was then as quick acting as the best seriesparallel thermopiles of later construction, and it is the most sensitive of all the thermopiles constructed of bismuth and silver.

Another example, which best illustrates the effect of emissivity upon sensitivity, is a thermopile (No. 2I), constructed of $0.1 \mathrm{~mm}$ wire pressed flat to reduce thermal conductivity to the cold junction. It consisted of 28 junctions in a receiver having a length of $14.5 \mathrm{~mm}$ (width or receiver $2 \mathrm{~mm}$; resistance $13.5 \mathrm{ohms}$ ). A test on a single junction of flat bismuth wire against a junction of the round wire (to which was attached a tin receiver) indicated a higher sensitivity for the flat wire. In the completed thermopile, however, the radiation sensitivity was 25 to 30 per cent less than the average sensitivity of a number of thermopiles constructed of the round wire, all of which thermopiles had closely ( 2 to 3 per cent) the same sensitivity. A test of the insulation showed that the individual receivers were in normal condition. Resmoking the surface did not change the sensitivity in a marked degree, and it was concluded that this lowering of the sensitivity was 
owing to the increased emissivity of the flat wires which presented an additional surface for radiation. This could be avoided to some extent by using fewer elements. This thermopile was unusually quick in its action, owing no doubt to reduction of thermal conduction along the wires. Thermopiles constructed of bismuth wires $0.15 \mathrm{~mm}$ in diameter, which were pressed flat, were found to be very fragile, and hence this mode of construction is not to be recommended.

A test was made of the radiation sensitivity of an element in which the receiver was a flat piece of bismuth. For this purpose one end of a bismuth wire $0.15 \mathrm{~mm}$ in diameter was pressed flat, as shown in Fig. $\mathrm{IH}$, and the silver wire was attached to it with Wood's alloy. To the other end of the wire (which was round) the silver wire and the tin receiver were attached in the usual manner. An area of the flattened bismuth, the size of the tin receiver was painted black. Assuming equality of the exposed areas, the receiver of flattened bismuth wire was 15 per cent more sensitive than the junction of round wire having the tin receiver; but it was defective in that it lagged in attaining temperature equilibrium when exposed to radiation.

Relation between external and internal resistance of a thermopile.In a previous paper ${ }^{17}$ it was found when the three units of a large surface thermopile were connected in series, thus producing an internal resistance which was about 6.4 times the external (galvanometer) resistance, that the radiation sensitivity was only about two-thirds (value plotted as a triangle, $\triangle$, in Fig. 2) that of the thermopile having the units joined in parallel, when the resistance was practically the same as that of the galvanometer.

In the recent experiments the external resistance was greater than the internal (thermopile) resistance. The data obtained in these experiments relate to 3 thermopiles and 2 galvanometers. Their importance will be evident from the fact that one of the first specifications of intending purchasers is that the resistances of the thermopile and the galvanometer must be equal. The most important tests of the sensitivity of a thermopile as a function of the external (galvanometer) resistance was made on the large thermopile shown in illustration No. 2 of Fig. 3. Its battered 
condition is owing to the hard usage given it as described below. This thermopile, No. 26, was constructed of bismuth wire o. $\mathrm{mm}$ in diameter (length $5 \mathrm{~mm}$ ) and silver wire $0.038 \mathrm{~mm}$ in diameter. The individual receivers of pure tin were 3 by $\mathrm{I} .5$ by $0.02 \mathrm{~mm}$, the central receiver being 3 by $23.6 \mathrm{~mm}$. There were 18 junctions, the total resistance being $13.95 \mathrm{ohms}$. Two additional leadwires were soldered to the thermopile; at the fourth and tenth junction. In this manner it was possible to study the behavior of $4,6,8$, 10, or 18 elements; having resistances (approximate) of $3.1,4.85,6.15,7.85$, and 13.95 ohms respectively. This thermopile was constructed for the "absolute radiometer" (see VIII) described on a subsequent page. It was discarded for that particular work because it had a slight shift of the zero reading ("creeping") after exposing it to radiation and because it was not as quick acting as was desired for absolute measurements. The slowness of response seemed to be due to the large receivers which, owing to the slowness of heat conduction from their extreme edges, lagged in attaining thermal equilibrium. This, however, did not interfere in making the following tests.

The galvanometer which was used in these tests consisted of four $26-\mathrm{ohm}$ coils mounted in Swedish iron shields ${ }^{18}$ as described in Note II. When the four coils were joined in series-parallel (26 ohms) the current sensitivity was twice that of the four coils in parallel (6.5 ohms). When all four coils were joined in series (IO4 ohms) the current sensitivity was not quite (about I per cent less than) four times that of the four coils in parallel $(6.5$ ohms); the complete period in all cases being the same, viz, four seconds.

Since the efficiency of the galvanometer is not under consideration we need not give it further discussion. The test is for conditions such as would be experienced in the average laboratory. It is assumed tentatively that the best conditions obtain when the external and the internal (thermopile) resistances are equal. The galvanometer period was kept constant, and the thermopile was exposed to a standard of radiation, ${ }^{19}$ consisting of a seasoned incandescent lamp operated at a constant temperature. In establishing this radiation standard it was found that the sensitivity of 
the thermopile was independent of the energy absorbed by the receiver. This test was applied by exposing the thermopile to a black body heated from 600 to $1100^{\circ} \mathrm{C}$., and the galvanometer deflections were found to be proportional to the energy falling upon the receiver.

Using a thermopile (No. 25) having a resistance of II.3 ohms, the same galvanometer deflection was observed when the galvanometer resistance was 26 ohms as when it was 6.5 ohms. In other words, the radiation sensitivity was the same when the external resistance was one-half and when it was twice the resistance of the thermopile. Exactly similar results were obtained with a thermopile (No. 23) having a resistance of 9.4 ohms when used with a

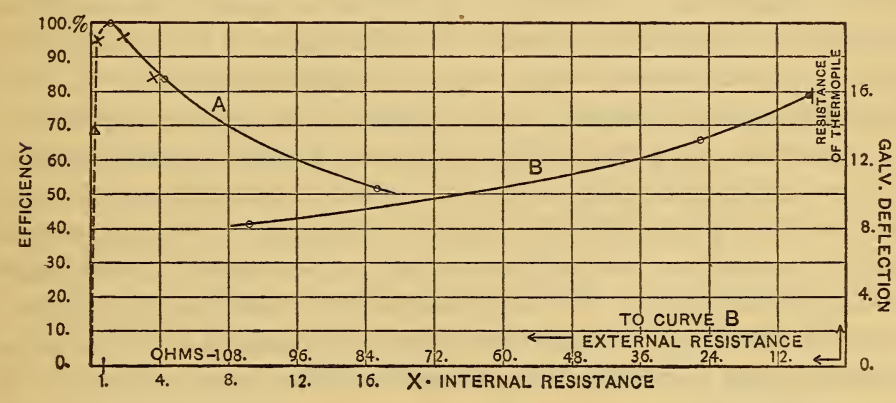

FIG. 2

four-coil galvanometer having a resistance of $5.3 \mathrm{ohms}$ (coils all in parallel) and $2 \mathrm{I}$ ohms (coils in series-parallel).

Using 9 junctions of the thermopile (No. 26) just described having $6.9 \mathrm{ohms}$ (and a galvanometer resistance of $26 \mathrm{ohms}$ ), the radiation sensitivity (galvanometer deflection) was about I 7 per cent less than that observed with a galvanometer resistance of 6.5 ohms. This test was repeated using 8 junctions of this thermopile giving a resistance of 6.2 ohms. The results are given in Fig. 2. Curve $\mathrm{B}$ gives the galvanometer deflections (ordinates) and the external resistance. Curve A gives the loss in sensitivity ("the efficiency") in per cent when the external resistance (the abscissæ) is $\mathrm{x}$-times the internal resistance, the efficiency being taken a maximum ( 100 per cent) when $x=I$. The crosses $(x . x)$ are 
for the subsidiary tests mentioned in the text. The results show that the galvanometer resistance may be twice the resistance of the thermopile (a condition one would not meet frequently in practice) without seriously affecting (decreasing by 5 per cent) the efficiency of the instrument. These results are in fair agreement with the theoretical deductions of Altenkirch, ${ }^{20}$ summarized on a preceding page.

During the past few years more than two score thermopiles and half a score of galvanometers have been constructed. The experience gained shows that the radiation sensitivity of the thermopile is dependent primarily upon the nicety of construction of the receivers and of the thermojunctions; and the galvanometer sensitivity is mainly a question of nicety of construction of the suspended system. If the voltage is to be measured with a potentiometer, then it is, of course, desirable to have a large number of elements joined in series. If the thermopile is to be used with a d'Arsonval galvanometer, it will be advantageous to have all the elements in series. In this manner there will be a gain in voltage and the increase in resistance of the thermopile may be utilized as part of the external, critical damping-resistance of the galvanometer. If the galvanometer is used as an ammeter, as is the usual custom, then the thermoelements are to be joined in series-parallel to produce a resistance of the same magnitude as that of the galvanometer. In this connection a single receiver, with several junctions of bismuth attached to it (to eliminate the lag of thermal conduction along the receiver), would no doubt be just as efficient when connected with a galvanometer of very low resistance.

Thermoelectric power of bismuth-silver.-The thermoelectric power of silver is low, and different samples were found to have the same value.

The thermoelectric power of various samples of bismuth wire was found to differ considerably. Of the eight samples tested (having diameters $0.06,0.08$, 0.I , and $0.15 \mathrm{~mm}$ ) the thermoelectric power, against silver, varied from 75 to 82 microvolts. This seemed to depend upon the purity of the material, as indicated by the purchases at different times. The bismuth wire received in 
one order of 0.08 and $0.1 \mathrm{~mm}$ had a thermoelectric power of 76 microvolts, while another order consisted of material giving, respectively, 75 and 82 microvolts. The resistance of the different samples of material was found quite constant, being of the order of o.I I ohms per millimeter length of wire o.I mm diameter.

\section{A THERMOPILE OF BISMUTH ALLOY}

The most recent investigations of Haken, ${ }^{21}$ and of Gelhoff and Neumeier, ${ }^{22}$ show that an alloy of $\mathrm{Bi}+9$ to Io per cent antimony has a thermoelectric power which varied from 77 to 87 microvolts. The writer has found, however, that alloys containing more than 5 per cent of antimony are too brittle for thermopiles. Moreover, different samples and different melts of the same sample of this alloy (supposed to contain the same amount of antimony) did not give the same thermoelectric power which varied from 61 to 85 microvolts. Apparently the physical structure has an influence upon the thermal emf. In cooling after casting the molten material upon a glass plate (as will be described presently) the antimony separates very easily from the bismuth and the alloy must be heated considerably above its melting point in order to form an intimate mixture, which is shown by the production of a smooth bright surface on the molten material. There is no special reason for using an alloy of bismuth instead of the pure bismuth, other than that it can be more easily soldered with Wood's alloy, which if too warm alloys with and renders pure bismuth too brittle for thermopiles. This alloy was therefore discarded and pure bismuth wire was employed as in previous thermopiles, because the best bismuth wire against silver has a thermal emf of +8 I microvolts per degree.

Tests showed that an alloy of bismuth containing 5 to 6 per cent of tin had a uniform (for different melts) thermal emf of -44 to -45 microvolts per degree. A thermoelement consisting of the best bismuth, and an alloy of $\mathrm{Bi}+5$ to 6 per cent tin gives a thermal emf of 125 to 127 microvolts per degree.

The bismuth and bismuth-tin alloy may be obtained from Hartmann and Braun in fine pliable wire from 0.06 to $0.15 \mathrm{~mm}$ diame-

${ }^{21}$ Haken, Verh. Phys. Gesell., 12, p. 229; 1910.

${ }^{22}$ Gelhoff and Neumeier, Phys. Gesell., 15, p. 876; 19ז 3. 
ter. This may be further reduced in size by cutting the wire in short lengths and pressing it flat between plates of glass. These flat pieces are then cut into narrow strips of the desired width.

The wire of bismuth-tin alloy may be made by allowing the molten metal to drop from a height upon a smooth perfectly clean glass plate ${ }^{23}$ which causes it to spatter into thin flat threads.

Pfund ${ }^{24}$ goes a step further, producing much longer filaments by hurling the molten metal over a glass plate. The spattering material is quite pliable. The wide strips increase the emissivity, so that for the same resistance of the round as compared with the flat material, the best width to balance emissivity and conductivity must be found by experiment.

A thermopile was constructed as shown in Fig. IA. The receivers were of platinum $0.005 \mathrm{~mm}$ in thickness and 1.8 by $2.5 \mathrm{~mm}$ in area. The heat capacity of this receiver, exclusive of the alloy wires, was a trifle less than that of the tin receivers. Hence its slow action to be mentioned presently must be attributed to the great heat capacity of the alloy wires. The bismuth wire was o. I $\mathrm{mm}$ diameter; the alloy was selected and estimated of a slightly greater area of cross section. The thermopile was constructed by melting a globule of pure tin ( $0.05 \mathrm{~mm}$ in diameter) to the receiver, using soldering solution to cause the tin to adhere to the platinum. The free end of the bismuth wire (joined to the silver wire by means of a tin bead as described in previous publications) was joined to the tin on the receivers. The wires of bismuth-tin alloy were then placed on the receivers (see Fig. IA) and secured with Wood's alloy, care being taken that the fusible alloy did not affect the bismuth wire, thus producing a brittle juncture. The end wires were attached to the binding posts by means of Wood's alloy. The front side of the receivers was painted with a mixture of lamp black and chemically precipitated platinum black, as previously described, ${ }^{25}$ and smoked with soot from a sperm candle.

Two elements were joined in series-parallel, thus reducing the resistance by one-fourth from what would be obtained by joining all the elements in series. The silver or copper end wire is used for three purposes: (I) to maintain a low resistance, (2) to maintain symmetry by having all the high emf junctions close together,

\footnotetext{
${ }^{23}$ This Bulletin, 7, p. 248; rgro. ${ }^{24}$ Pfund: Phys. Rev., 34, p. 228; rgr2. ${ }^{25}$ This Bulletin, 9, p. 7; rgra.
} 
freely in contact with the air, (3) to secure greater strength. The bismuth wire can not be easily attached to binding posts, and although pliable it is not advisable to subject it to torsional strains. The additional length of wire (of negligible resistance) at the ends of the bismuth adds pliability, which is needed in a commercial instrument subjected to rough usage. No shellac was used except for covering the silver wire and for insulation at the overlapping edges of the central line of receivers.

The radiation sensitivity of this thermopile was not quite as high as it was hoped to attain; neither was it as quick acting as the thermopiles of pure bismuth containing less metal in the receiver. However, as a first attempt at this design, the knowledge gained indicates where improvements may be made by using finer wires of the alloy. The resistance of this thermopile was 3.8 ohms. The thermal sensitivity (thermoelectric power) was about 55 per cent greater than the bismuth silver thermopile. The radiation sensitivity was 20 to $2 \mathrm{I}$ per cent ${ }^{26}$ greater than the average sensitivity of a number of bismuth-silver thermopiles of the type having all the elements in series, and only 4 to 5 per cent more sensitive than the best thermopiles of bismuth silver having two elements joined in series-parallel. For some researches it will be of advantage to construct a thermopile of bismuth-tin alloy. However, from the results obtained with this thermopile it is evident that the radiation sensitivity is more dependent upon fineness of material, smallness of heat capacity, and neatness of construction than upon the thermoelectric power of the material used.

\section{A THERMOPILE OF BISMUTH IRON}

The first metal tried with bismuth was iron, but it proved a failure ${ }^{27}$ owing to the use of Wood's alloy, which produced a brittle juncture with the bismuth. After gaining the experience in constructing more than two score linear thermopiles, including every design mentioned in this paper, it seemed but fair to make another test of the combination of bismuth and iron. The iron used had a thermoelectric power of $+\mathrm{I} 3.5$ microvolts against silver as com-

${ }^{26}$ In the preliminary note (Amer. Phys. Soc., No. $28,191_{3}$ ) the value of 30 to 31 per cent is given. This higher value is owing to the fact that no corrections were made for differences in external and internal resistance.

${ }_{27}$ This Bulletin, 9, p. 7; I9r2. 
pared with -80 microvolts for bismuth silver. The diameter of the bismuth wire was $0.1 \mathrm{~mm}$, and that of the iron wire was 0.036 $\mathrm{mm}$. The lengths of the wires were $3.5 \mathrm{~mm}$ for the iron and $3 \mathrm{~mm}$ for the bismuth. The latter wire was made somewhat shorter than usual, owing to the manner of construction, as shown in Fig. $\mathrm{ID}^{\prime}$. For convenience in construction the two bismuth wires were joined in the form of a "Y" to a copper wire $0.08 \mathrm{~mm}$ in diameter. By introducing the copper wire all the high thermal emf junctures (bismuth iron and bismuth copper) are free in air and the resistance is kept low, as explained in Part V of this paper. The ratio of diameters of the wires is closely that required by theory. The receivers were of tin 2.0 by $\mathrm{I} .8$ by $0.02 \mathrm{~mm}$ as used in the bismuthsilver thermopiles. In fact everything was kept the same except the substitution of iron for silver, to determine the effect of the iron wire upon the sensitivity.

The thermopile was constructed in the same manner as described for the other thermopiles. The iron wires were cut to the proper lengths and pressed straight, but not annealed. A small globule of tin was then attached to the iron wire (as was done with the silver wire), the ends of the wire being first dipped in the zinc chloride solution. No difficulty was experienced in causing the tin globule to surround and adhere to the iron, as was experienced in the first work. This was owing to the fact that the wire was quite new and free from oxidation and tarnish. The bismuth wire was fused to the iron wire in the same manner as it was attached to the silver wire. In the completed instrument the iron wires were covered with shellac to prevent rusting. The completed thermopile consisted of 16 elements joined two in series parallel, forming a receiving surface 1.8 by $16.5 \mathrm{~mm}$ and having a resistance of $3.23 \mathrm{ohms}$. The resistance is therefore about 90 per cent higher than that of the bismuth-silver thermopile, constructed alongside with the one of bismuth-iron (bismuth wire $0.1 \mathrm{~mm}$; silver wire 0.036 ; resistance of the 8 double junctions r. 84 ohms; area 1.8 by $16.7 \mathrm{~mm}$ ).

The results of the sensitivity tests were rather disappointing, but they were not unexpected in view of the fact that the internal resistance was practically doubled while the thermal emf was increased only about 18 per cent. The sensitivity of the bismuth- 
iron thermopile was 27 to 28 (arbitrary scale), which is 5 to 6 per cent below the average sensitivity of the bismuth-silver thermopile. The sensitivity of the bismuth-silver thermopile was 30 to $3 \mathrm{I}$, which was somewhat higher than the average sensitivity of the series-parallel design of bismuth-silver thermopiles.

The bismuth-iron thermopile was free from drift and appeared to have all the requirements of a good radiometer. From this it appears that but little gain was to be expected by bettering the workmanship, by constructing additional thermopiles of bismuth iron. The failure of the bismuth-iron thermopiles to show a higher sensitivity than the thermopile of bismuth silver appears to be due to the increased internal resistance of the former, which counteracts the sensitivity which is gained by increasing the thermoelectric power. From the experience gained with the thermopile of bismuth alloys no great gain in sensitivity was expected, but it seemed desirable to give the matter a fair trial. The only way to do so seemed to be to construct the complete instrument as used in practical work. In a preliminary test (using a juncture of iron and one of silver, with the bismuth wire between them; receivers of tin, $\mathrm{I}$ by $3 \mathrm{~mm}$ ) the iron-bismuth junction was 28 per cent more sensitive than the one of silver bismuth. Here, of course, the internal resistance was the same for both junctions, and the sensitivity test applied to conditions which were different from those found in practice. In view of the general notion that a high thermoelectric power (without considering the specific resistance of the material) will produce a thermopile having a high radiation sensitivity, it is important to notice that this experiment is convincing proof to the contrary. As indicated by Haken ${ }^{28}$ the pure metals, not alloys, should be used; and from the herein-described experiments, bismuth (with its unusually high thermoelectric power as compared with its resistance) seems the most satisfactory of all.

Fine wires of copper, silver, iron, etc., seem unusually susceptible to corrosion, and the next step is to find a wire which is as easily handled as is silver, but which is free from corrosion. Gold and platinum are promising, but the latter has a high resistance and the 
former becomes brittle when soldered with materials containing lead.

Probably the best combination producing a long-lived instrument is bismuth wire joined to the receivers as shown in Fig. ID, with short wires of pure platinum (substituted for the bismuth in Fig. $\mathrm{ID}^{\prime}$ ) joined to a heavy (O.I mm diameter) copper wire, as shown in the $\mathrm{Y}$-form of Fig. $\mathrm{ID}^{\prime}$. In this manner of construction it would be unnecessary to cover the wires with shellac to prevent corrosion. The coating of shellac, however, does not appreciably increase the heat capacity or emissivity of the wires. In fact, it seems to reduce somewhat the effect of convection currents, which, as is well known, are most effective upon very fine wires. According to the writer's experience, lacquers containing amyl acetate should not be applied to the bismuth juncture. The solvent of the lacquer seemed to attack the juncture, producing a high resistance.

\section{A RADIOMETER ATTACHMENT FOR MONOCHROMATIC ILLUMI- NATORS}

At the present day visible and ultraviolent radiations are being extensively used as stimuli in biological, chemical, physical, and physiological investigations. As already stated, it is desirable in all cases to know the energy value (mechanical equivalent) comprised in the different wave lengths used as stimuli. For this purpose it is necessary to use a radiometer which functions independently of the frequency (wave length) of the stimulus. The most useful radiometer, which requires but little care, and which can be operated by experimenters having had but little experience in physical manipulations, is a thermopile. The bismuth-silver thermopile with its completely opaque (i. e., no openings in it) receiver is especially applicable to such radiometric measurements because of its high sensitivity and because it intercepts all the radiations falling within a given area. The latter is an important requirement ${ }^{29}$ in radiometric measurements involving the relative amounts of energy in different parts of the spectrum, which energy distribution is affected by the change in focal length of the spec- 


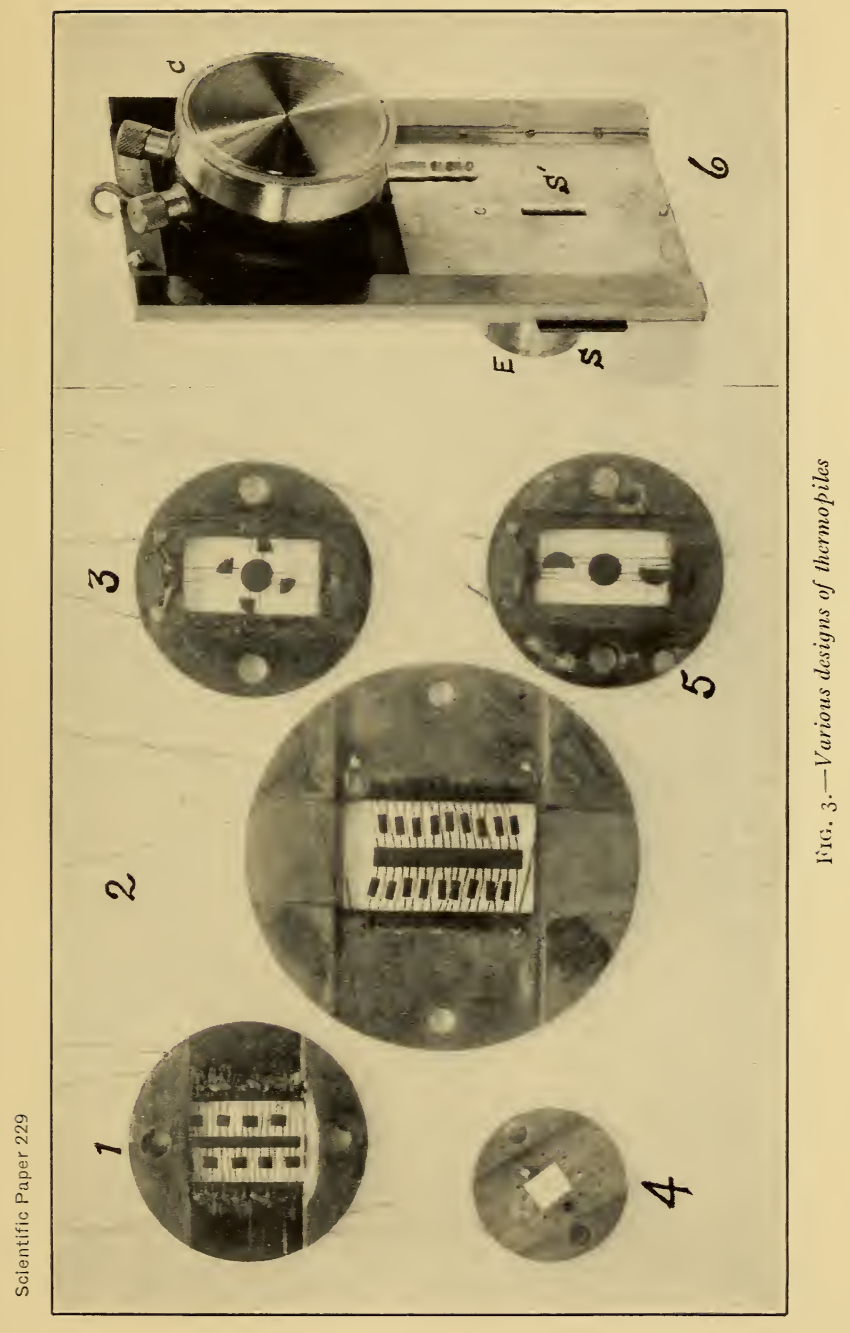


trometer lenses. However, a knowledge of the distribution of energy in the spectrum of the source of radiation is generally not required in the measurement of light stimuli.

As an attachment to a monochromatic illuminator, the thermopile, Fig. IA is mounted in a metal box B of Fig. 4 which can be closed air-tight by means of a cap, $\mathrm{C}$, and evacuated through the outlet, D. A window, W, of quartz is placed over the silt. The metal box, containing the thermopile, moves in vertical ways, $\mathrm{A}$, Fig. 4, which are attached to the adapter, E, thus displacing the eyepiece of the spectrometer. The slit, S, as constructed, is securely fastened to the telescope tube, thus preventing any accidental displacement of the thermopile in the spectrum. It was with the forethought of such a possible displacement, when the box is raised and lowered, that the slit was thus secured instead of attaching it to the box containing the thermopile. The jaws of the slit have their knife edges facing the incident radiations thus providing a sharp separation of the rays and thus eliminating a possible reflection of radiations from the slanting sides into the thermopile case. A somewhat better view of some parts of this attachment is shown in the photographic reproduction, No. 6, of Fig. 3, where the thermopile box is in the raised position, thus permitting the radiations coming through the exit slit, S, to pass out into space. In Fig. 3 the lettering corresponds with the lettering of similar parts in Fig. 4.

When it is desired to measure the intensity of the emergent radiations, the thermopile is lowered in front of the slit S, Fig. 3 . When it is desired to have the light pass out into space, or when it is desired to make any adjustments or to test the calibration, the thermopile is raised above the slit as shown in Figs. 3 and 4 . The "zero setting," say, upon the yellow helium line may be made as accurately within the slit, as it can be made upon a bolometer strip. For this purpose the small telescope or microscope used with the spectrobolometer, as previously described, is focused upon the slit (through S of Fig. 4). The slit jaws have, of course, been given the curvature of the spectral lines. The spectrometer circle is read, say, when the spectral line passes out of sight back of the right-hand jaw of the slit. The spectrometer circle is then read when the spectral line passes back of the left-hand jaw of the 

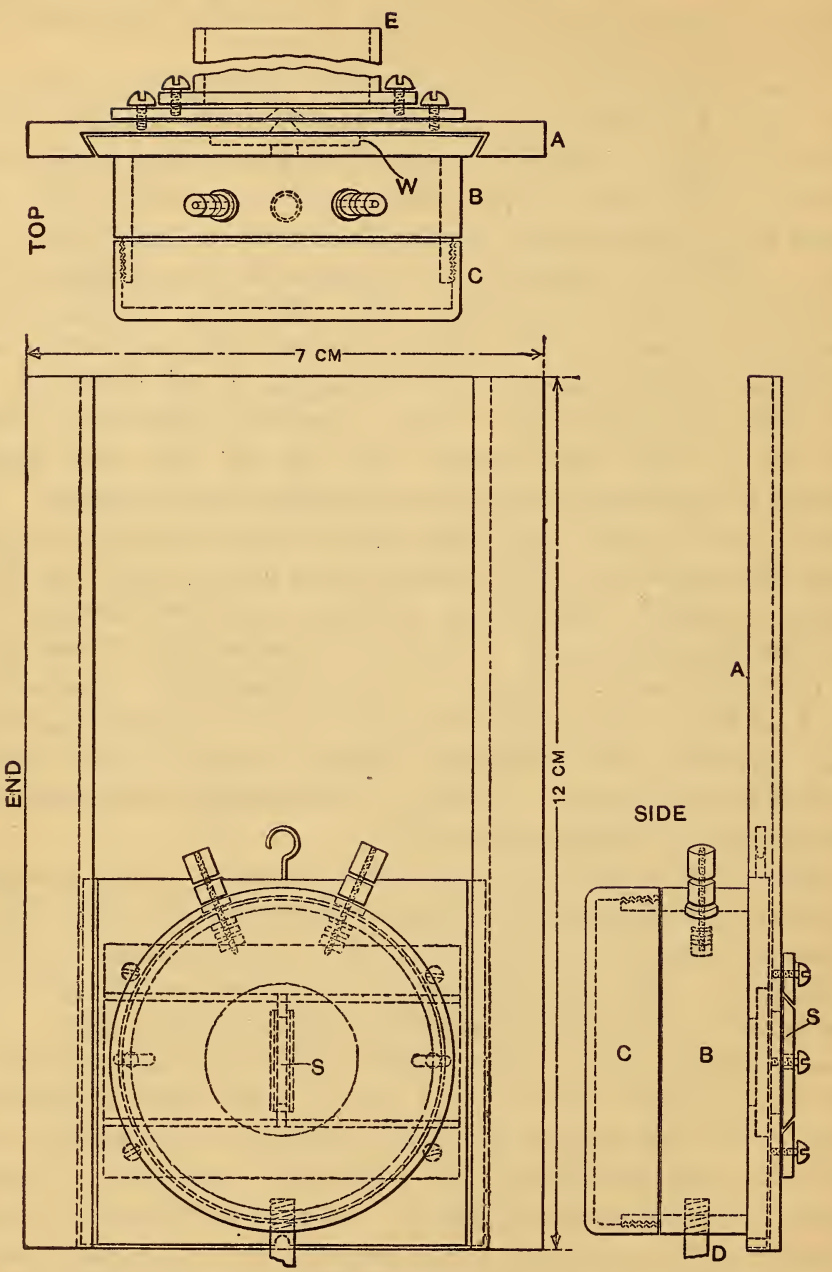

FIG. 4.-Radiometer attachment for monochromatic illuminators 
slit. The spectrometer reading half way between these two points is the true setting to cause the spectral line to fall within the exit slit which is usually made the same opening as the collimator slit.

\section{A THERMOPILE FOR ABSOLUTE MEASUREMENTS OF RADIATION}

The pyrheliometer as designed by Ångström ${ }^{30}$ consists of a thermoelement of iron and constantan attached to a thin strip of manganin (a thin layer of sillk intervening for insulation) which acts as a receiver to intercept the radiant energy, and also as a heater through which an electric current may be passed to produce the same rise in temperature as that of the absorbed radiant energy. From the resistance of the strip, the electric current through it, and the area exposed to radiation, the absolute value of the radiant energy may be determined.

In this form of construction the manganin strip and the thermoelement may become separated, thus changing the sensitivity and the constants of the instrument. As mentioned in the preceding paper ${ }^{31}$ on radiation instruments, it was proposed to apply the bismuth-silver thermopile to this form of radiometer, which seems to have many commendable features. In the meantime Gerlach, ${ }^{32}$ at the suggestion of Paschen, has carried out a series of experiments and has obtained very satisfactory results with a modification of the Ảngström radiometer. This modification consists in having the thermoelement (in reality a series of elements, a thermopile, of iron and constantan wires, with receivers rolled flat) detached from the heater-receiver of manganin, thus eliminating the possibility of variable contact. The thermopile is therefore heated primarily by radiation; but from the experience with the writer's design, this device is far more sensitive than ordinarily required and hence direct metallic contact is unnecessary. In fact for quickness of action and for electrical insulation it is desirable to have the manganin heater and the thermopile separated, to reduce the extra heat capacity of the insulating materials. Much of Gerlach's work having been published before great progress had been made on the most efficient form of the present

so Ångström: Ann. der Phys. (3), p. 294, I890; (3), p. 663, I899; Phys. Rev., 1, p. 365, 1893.

31 This Bulletin, 9, p. 31 , I9x.

32 Gerlach: Ann. der Phys. (4), 38, p. x, r9r2.

$68976^{\circ}-14-11$ 
design, advantage was taken of his experience in making further improvements which consists principally in the construction of the heater-receiver. The thermopiles differ, of course, in that the one of bismuth silver has a continuous receiving surface, which increases the sensitivity. The sensitivity is also materially increased (doubled) by the use of bismuth silver instead of iron and constantan. In the Gerlach instrument the potential terminals are attached to the heavy copper electrodes supporting the thin manganin strip. About $1.5 \mathrm{~mm}$ of each end of this manganin strip is shielded from radiation. This amount of covering of the ends of the manganin strip was found experimentally to give uniform values to the constant of radiation. When the ends were not covered his values were smaller owing to heat conduction to the electrodes. As will be shown in a forthcoming paper dealing with radiation measurements, the measurement of the electrical energy expended in the whole strip and comparing it with the heat developed by radiation falling upon only part of the strip may give erroneous values.

In the present instrument the potential terminals are about $3 \mathrm{~mm}$ from the points where the ends of the thin metal strip are attached to the copper electrodes. The nichrome heater already described is used in soldering these wires. The potential wires are of fine platinum, $0.0055 \mathrm{~mm}$ in diameter. It is obtained from Wollaston wire having the silver removed from about $5 \mathrm{~mm}$ of the end which is attached to the receiver. There is practically no heat conduction along this fine platinum wire since the contact is a mere point on the longitudinal axis of the strip. The ends of the slit forming the opening in the receiver terminate directly over these potential terminals. Tests made with, and without, these coverings across the ends showed no observable difference in the radiation measurements. Provision has also been made to use the instrument without the slit jaws covering the strip. Using the receiver in this manner, the area of the strip exposed to radiation is defined by its full width, and by the distance between the potential terminals. A similar design of heater has been used by Bauer and Moulin ${ }^{33}$ as a source of radiation. By placing the potential terminals at a distance from the electrodes 
the measurement of the electric energy put into the thin metal strip pertains only to that part which is exposed to radiation. The thermopile is somewhat shorter than this exposed strip and it is further protected by shields so that no radiation from that part of the strip, lying between the potential terminals and the electrodes, can fall upon the thermopile receiver. In fact the whole thermopile (excepting the central receiver) is covered with a thick screen of cardboard to provide electrical insulation and
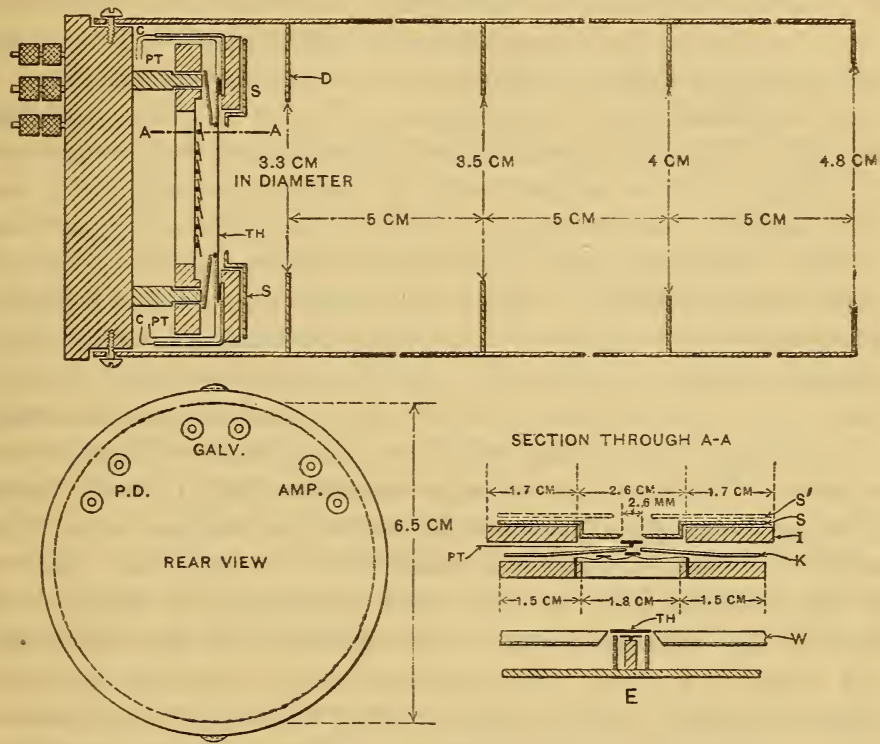

FIG. 5.-Thermopile for absolute measurements of radiation

to shield it from radiation. In front of the cardboard are two copper plates, $\mathrm{K}, 0.8 \mathrm{~mm}$ in thickness, which are painted black and smoked on the side facing the receiver-heater. In Fig. 5 are shown the essential parts of the thermopile as used in the absolute measurements. It consists of the slits, $\mathrm{S}$, of brass or aluminum 1.2 to $1.8 \mathrm{~mm}$ in thickness. The insulating support, I, is of slate, upon which is mounted the "therlo," Th, manganin or platinum strip. The potential wires of platinum, Pt, are mounted on the 
rear side of this receiver-heater. The electrodes, C, are of copper. One sample of "therlo," used was $5.5 \mathrm{~mm}$ wide, about $0.007 \mathrm{~mm}$ thick, $29.5 \mathrm{~mm}$ long between the electrodes, and $23.5 \mathrm{~mm}$ distance between the potential terminals. Using a receiver of bolometer platinum, which is much thinner than the "therlo" used, temperature equilibrium was attained in about 12 seconds. Some of the samples used were 4 to $5 \mathrm{~mm}$ in width. Receivers of bolometer platinum are much quicker than the thicker samples of "therlo" in attaining temperature equilibrium. However, the preliminary measurements of the Stefan constant of total radiation, as observed with these two kinds of receivers, are in excellent agreement.

In the lower right hand corner of Fig. 5 is given a section through $\mathrm{A}-\mathrm{A}$ (viewed from above) which shows the arrangement of the slits, $\mathrm{S}$, the receiver with its potential terminal, $\mathrm{Pt}$, and the thermopile with the metal shields covering the cold junctions.

Four thermopiles were constructed before one was found as quick acting as desired. One of the thermopiles used in radiation measurements consisted of ro double junctions joined in seriesparallel as shown in Fig. ID. In this instrument each receiver was I $\mathrm{mm}$ wide and two of these were joined in parallel instead of the design (Fig. IA) in which two elements are joined to one receiver. This insures a stronger junction which is easily tested for tensile strength. The area of the central receiver was $\mathrm{I} .8$ by I $8.6 \mathrm{~mm}$. This receiver was raised about $\mathrm{I} \mathrm{mm}$ above the rest of the wires forming the pile, thus permitting its being placed close to the heater-receiver. The resistance of this thermopile was about 7.9 ohms. The bismuth wire used was $0.06 \mathrm{~mm}$ diameter (length $4.5 \mathrm{~mm}$ ) and the silver was $0.0308 \mathrm{~mm}$ diameter which explains the high resistance. The radiation sensitivity was up to the highest yet attained and the maximum deflection was attained in but a slightly greater time than (I.3 times) that of the galvanometer period. For example, using a galvanometer single swing of 3 seconds, the maximum deflection caused by warming the heater (whether heated electrically or heated by the absorption of radiant energy) occurred in less than 8 seconds. The radiation sensitivity was such that $\mathrm{I}$ microwatt of radiant energy produced about 0.19 microvolts or a rise in temperature

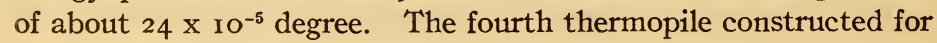


use in this instrument for making absolute measurements contained bismuth wire o.I $\mathrm{mm}$ in diameter and $45 \mathrm{~mm}$ in length. The elements were joined two in series-parallel as shown in illustration No. I of Fig. 3. Its sensitivity was the same (within 2 per cent, which is the normal variation for different thermopiles) as that of the instruments constructed of bismuth wire $3.5 \mathrm{~mm}$ in length. This is a further test to the one given on a previous page, showing that a length of $3.5 \mathrm{~mm}$ is sufficient to prevent a reduction in sensitivity by warming of the cold junction by heat conducted from the exposed junction.

The slit jaws were about $\mathrm{I} \mathrm{mm}$ in front of the receiver and the thermopile was about I.5 mm back of it. Gerlach's extensive tests show that the amount of overlapping of the receiver by the slit jaws does not affect the observations. Various electrical tests, e. g., reversing the current in the heater-receiver, showed that it was thoroughly insulated from the thermopile. Covering the opening in the slit jaws with a sheet of thick aluminum (bright and smoked) and exposing the instrument to intense radiation, showed no appreciable warming. This shows that in the short time that the instrument is exposed to radiation, the slit jaws are not sufficiently warmed to cause an appreciable radiation from them, upon the heater-receiver. When the whole receiver is exposed to radiation, these slit jaws are separated by a slightly greater amount than the width of the strip. The small amount of radiation which passes between the slit jaws and the edges of the receiver is absorbed by the smoked copper surfaces (K, Fig. 5) at the rear.

To prevent stray radiations from falling upon the receiver various arrangements of the slits and diaphragms were tried. One of these combinations tried was a slit $\mathrm{S}$ and a diaphragm $\mathrm{S}^{\prime}$, as shown in Fig. 5A-A. In this arrangement the diaphragm $S^{\prime}$ is of copper I $\mathrm{mm}$ in thickness painted with lampblack and smoked on both sides. The slit $\mathrm{S}$, of aluminum, 1.2 to $\mathrm{I} .8 \mathrm{~mm}$ in thickness, is painted black, excepting a border about $5 \mathrm{~mm}$ wide, along the knife edge, which is highly polished. The four brass diaphragms (Fig. 5) and the inside of the brass tube which supports them are entirely covered with lampblack paint and smoked in the flame of sperm candle. In this manner most of the radia- 
tions in the wide cone of rays emanating from the black body are absorbed at some distance from the receiver and hence there is but little chance for stray radiations to fall upon the receiver. The narrow, bright strip along the knife edge of the slit $\mathrm{S}$ absorbs but little radiation. The heat developed by absorption of radiation is speedily conducted away laterally from the knife edge. The shield $S^{\prime}$ is sufficiently heavy, so that (judging from the experience gained in a previous investigation of the diffuse reflecting power of lampblack) the temperature can not rise sufficiently to produce reradiation upon the receiver. In subsequent work this shield was placed upon the innermost diaphragm, D, which had an opening $3.3 \mathrm{~cm}$ in diameter, thus lessening the amount of diffuse rediation that might fall upon the receiver.

Attention has already been called to the fact that the "cold" deposits of soot from a sperm candle reflects diffusibly about I.2 per cent. The diffuse reflecting power of soot, deposited by holding a cold metal plate in the tip of the flame of a sperm candle (or better still, an acetylene flame) is much lower in value, being of the order of 0.5 to 0.6 per cent.

From the foregoing description of the instrument as thus far developed, it may be seen that there is but little in common with Gerlach's device. The instrument is very sensitive, so that variation in the radiation from a black body caused by a variation of $0^{\circ} . \mathrm{I}$ in temperature, at $800^{\circ}$ to $900^{\circ} \mathrm{C}$, was easily observed in the galvanometer deflections. Using a platinum receiver, the galvanometer deflection registers a maximum in 8 seconds. The instrument is easily and quickly operated, and hence if all the sources of stray radiations can be eliminated it promises to be an accurate pyrometer for refined temperature measurements. For this purpose it will be desirable to modify the instrument so that the various shields and diaphragms, W, may be water-cooled, as shown in Fig. $5 \mathrm{E}$. In this design the thermopile, mounted as shown in Fig. IG, is entirely inclosed and shielded from diffuse radiations.

The energy expended in heating the receiver is determined by measuring the drop in potential along the part of the strip exposed to radiation and the electric current through the strip. The current is determined by measuring the drop in potential across 
a standard resistence of $\mathrm{I} \mathrm{ohm}$. When using a manganin or "therlo" receiver the resistance may be determined so that only the measurement of the current is necessary. The emfs are measured with a Leeds \& Northrup type $\mathrm{K}$ potentiometer.

In view of the fact that this paper does not deal with the constants of total radiation, it will be sufficient to add that the numerical value of this constant as thus far observed with this type of radiometer is somewhat lower than Gerlach's value obtained with a somewhat similar instrument.

\section{SPECIAL DESIGNS OF THERMOPILES}

Stellar thermoelements. ${ }^{33 a}$-A stellar radiometer differs from a laboratory instrument in that no shutter is required. Here the sky is the shutter and the observation consists in exposing the thermopile receiver alternately to a star and to the adjoining sky. Or, by exposing the two junctions alternately the deflections (in opposite directions) are doubled. In a refracting telescope the thermopile is shielded from nearby sky and water radiation, which is of wave lengths which are absorbed by the glass lenses. The zero reading therefore depends upon the temperature of the lenses forming the objective. In a reflector the thermopile (when in an inclosure having a fluorite or rock-salt window) radiates to the sky, and it is desirable to have the two junctions (receivers) of as nearly the same size and emissivity as is possible to construct them, in order to maintain symmetry. There is no apparent gain in using more than two junctions, because of the difficulty in maintaining symmetry and because of the difficulty of construction.

In the first experiments on thermopiles it was deemed desirable to use several elements in the receiver, and a thermopile was described which had ro elements meeting at a point, with a receiver I $\mathrm{mm}$ in diameter. However, a star image is a mere point any way, hence, the receiver should be reduced to the smallest workable dimensions.

A high emf, small heat capacity, and symmetry of receivers are required. However, from the foregoing experiments it is evident that if the heat capacity of bismuth alloys can not be kept low, it is better to use the pure metal in spite of the fact that the 
thermoelectric power is 50 per cent lower. The sensitivity is increased from four to five times by placing the thermoelements invacuum. The time to attain temperature equilibrium does not appear to be appreciably increased when the elements are in vacuum.

A further increase in the sensitivity is obtained by lengthening the period of the galvanometer.

Whether, under these conditions the point receiver thermopile can be made more sensitive than a bolometer, remains to be determined. In view of the fact that the heat conducted along the bolometer strip serves to change the resistance, while in the thermopile it is an impediment, it may be found in practice that the vacuum bolometer can be made more sensitive than the thermopile. ${ }^{33 b}$

Several stellar thermopiles were constructed, as shown in illustration No. 4 of Fig. 3, in which the receivers are 0.3 to $0.4 \mathrm{~mm}$ in diameter. The thermopile shown in Fig. $\mathrm{IF}$, having two elements in each receiver has not yet been tried. The distance between the two receivers is made $0.5 \mathrm{~mm}$ or less so as to facilitate exposing them alternately to a star image. Except by making an intercomparison against an arbitrary point source of radiation similar to a star image, there is no fair way of specifying the sensitivity, owing to the variable size of the receivers. It is hoped to compare the radiation from a star (e. g., Arcturus) with an artificial star and thereby establish a fair standard of comparison of this type of radiometer.

In the stellar thermopiles, as shown in Fig. $\mathrm{IF}$, and in No. 4, of Fig. 3, a short piece of bismuth wire $0.06 \mathrm{~mm}$ in diameter was pressed flat between two pieces of plate glass. The thickness was then 0.01 to $0.012 \mathrm{~mm}$. This was then cut into narrow strips, perhaps $0.05 \mathrm{~mm}$ wide, by means of a sharp razor. These narrow strips were pressed to about 3 times their former width, and again cut into strips $0.03 \mathrm{~mm}$ to $0.07 \mathrm{~mm}$ in width. The estimated thickness was $0.005 \mathrm{~mm}$. The silver wire used was $0.0165 \mathrm{~mm}$ in diameter. Fine globules (perhaps 0.03 to $0.05 \mathrm{~mm}$ in diameter) of tin were then attached to the silver wires and pressed to 0.3 to $0.4 \mathrm{~mm}$ diameter. The bismuth wire (about $2 \mathrm{~mm}$ long) was then

\footnotetext{
33b However, in the preliminary tests, to be given in a forthcoming paper on stellar radiation measurements, the thermocouple was found more sensitive than the bolometer.
} 
fused to this tin receiver. Wood's alloy was used to attach the silver wires to the binding posts. The receivers were painted with the previously described mixture of lampblack and platinum black, but not smoked. The resistance of such a thermoelement is from 2 to 2.8 ohms, depending upon the length of the bismuth wire. Elements were also constructed of bismuth alloys, of bismuth and platinum (Wollaston wire 0.005 to $0.01 \mathrm{~mm}$ in diameter) and of bismuth iron. They were mounted together in a receiver and tested under the same conditions. The bismuth-platinum element had a resistance of 5 to 6 ohms, half of which was contributed by the platinum. One bismuth-platinum thermoelement consisted of bismuth $\mathrm{I} .9 \mathrm{~mm}$ in length and $0.07 \mathrm{Im}$ in width. The platinum was $0.01 \mathrm{~mm}$ in diameter. The receivers of tin were respectively 0.29 and $0.33 \mathrm{~mm}$ in diameter. Its resistance was 4.58 ohms. It was more than twice as sensitive as the best bismuth silver $(\mathrm{Ag}=0.0165 \mathrm{~mm}$ diameter $)$ thermoelements of similar dimensions. This is owing to the fact that platinum has a much lower heat conductivity than silver. This thermoelement of bismuth-platinum, having a thermoelectric power of 80 to 85 microvolts, was found to be at least 25 per cent more sensitive than a similar thermoelement of bismuth, and an alloy of bismuth +5 per cent tin which had a thermoelectric power of I 27 microvolts. In the bismuth-bismuth alloy thermoelement the length of the bismuth was $2.2 \mathrm{~mm}$, the width was $0.067 \mathrm{~mm}$, and the resistance of the element was II.55 ohms. The receivers were respectively 0.38 and $0.44 \mathrm{~mm}$ in diameter. Both elements were mounted in the same inclosure and tested against the same artificial star. The latter was a cylindrical acetylene flame with a pinhole opening in a diaphragm, which was placed in front of the flame. An image of this pinhole was projected upon the receiver. It is hoped to compare these with a vacuum bolometer of small heat capacity to determine the merits of these two types (bolometer and thermopile) of stellar radiometers. In such a test the bolometer and thermopile are to be mounted together in the same container. The evacuation of the air is produced by heating metallic calcium which is contained in a quartz tube.

An absolute thermopile for the measurement of nocturnal radiation.-On a previous page attention was called to the Ảngström 
pyrheliometer modified so as to reduce its heat capacity and hence render it quicker in its action by having the thermopile separated from the heater receiver. For the measurement of nocturnal radiation, which generally is a passage of radiation from the surface of the thermopile outward into space, a more massive heater receiver in contact with the thermopile is permissible, in order to minimize the effect of air currents.

The pyrheliometer of Ångström ${ }^{34}$, as used for the measurement of nocturnal radiation, consists of two manganin strips, to each of which is attached a single thermoelement of iron and constantan. One strip is kept bright to prevent cooling by radiation. The other one is blackened to facilitate radiation, and hence undergoes the greatest changes in temperature, which is usually a cooling, since, on clear nights there is a passage of terrestrial radiation into space. An electric current is passed through this manganin strip to compensate for the cooling. From the resistance of the strip, the area, etc., the loss of radiation into space, may be determined in absolute measure.

In the present design, Fig. IC, the thermoelements $(\mathrm{Bi}-$ o.I $\mathrm{mm} ; \mathrm{Ag}=0.036 \mathrm{~mm}$ diameter. Receivers of tin $\mathrm{I} .4$ by $\mathrm{I} .8$ by $0.02 \mathrm{~mm}$ ) are cemented directly to the four manganin strips, $0.033 \mathrm{~mm}$ in thickness and $2 \mathrm{~mm}$ in width, which are alternately black and bright. For the latter purpose the front surfaces are plated with a thin layer of gold. The reflecting power of lampblack for long waves is about 3 per cent, and for gold it is about 97 per cent. The difference in the emissivities of these two surfaces should produce a far greater difference in temperature within the strips than is possible with a metallic surface having a lower reflecting power. For convenience in construction the thermoelements are in four rows, joined across the back of the mounting, as shown in the illustration. This part of the device was designed and constructed for the United States Weather Bureau for nocturnal radiation measurements. The instrument gave a maximum deflection in 15 seconds (galvanometer swing was 3 seconds) when exposed to a standard of radiation from which it appears that cementing the receivers directly in contact with the heavy man-

\footnotetext{
3 K. Ångström: Nova Acta Reg. Soc. Scient. Upsala (4), 1, No. 2, 1905; A. Ångström: Astrophys. J.。 37 , p. 305,1913 .
} 
ganin strip does not seriously increase the heat capacity and hence the period of the instrument.

A thermopile for physiological problems.-An important problem in physiology is to determine definitely whether or not heat is evolved by a live nerve during tetanization. If there is a chemical reaction (oxidation of a carbohydrate in order to expedite a nervous wave) when the nerve is undergoing tetanus, either by an electrical or by a chemical stimulus, then there should be an evolution of heat with a consequent rise in temperature. The attempt was made by Hill ${ }^{35}$ to detect such a rise in temperature during the transmission of a nervous impulse by placing the exercised sciatic nerve of a frog upon the central row of thermo junctions (30 in number) of a Rubens iron-constantan thermopile. The receivers were small and hence could not make very effective contact with the nerve.

The proposition having been presented to design a bismuthsilver thermopile to meet the requirements of this problem, the modification illustrated in Fig. IE was constructed. The device, which contains 20 thermo elements joined in series, was constructed of bismuth wire o. $\mathrm{mm}$ in diameter, and silver wire $0.038 \mathrm{~mm}$ in diameter, the resistance being $9.45 \mathrm{ohms}$. The novelty in this thermopile consists in having the receivers bent into a $U$-shaped trough, $21.5 \mathrm{~mm}$ long and about $1.2 \mathrm{~mm}$ deep. The inside of each receiver was painted with lamp black and hence would acquire heat (if any be produced) by conduction and by radiation. For symmetry, samples of the material (nerve, muscle) under examination are placed in both troughs, and by exciting them alternately the galvanometer deflection (in opposite directions) will be doubled.

The sensitivity was tested by placing an insulated manganin wire $0.05 \mathrm{~mm}$ in diameter in the $U$-shaped receiver and passing through it an electric current of o.oor ampere, which produced a large deflection $(25+\mathrm{cm})$ of the galvanometer. The test showed that using a galvanometer sensitivity of $i=5 \times 10^{-10}$ ampere, a deflection of $\mathrm{I} \mathrm{mm}=3.8 \times 10^{-8} \mathrm{watt}=9 \times \mathrm{IO}^{-9} \mathrm{~g}$-cal. sec. ${ }^{-1}$. The sensitivity was, of course, higher than this, for the wire heater did not lie closely throughout its whole length in contact with the receiver. 
In the hands of an experienced operator the galvanometer sensitivity could be increased 5 times, and reading to $0.2 \mathrm{~mm}$ it is safe to estimate that, with this device, an evolution of heat at the rate of I X $\mathrm{IO}^{-10} \mathrm{~g}$-cal. $\mathrm{sec}^{-1}$ can be detected.

This thermopile behaved exactly as the others with flat receivers. It was entirely free from drift and produced a maximum deflection in $4 / 3$ the free swing of the galvanometer. As an ammeter this device should be useful for certain classes of measurements of electrical currents. In the latter application, however, the heater would no doubt be more efficient in the form of a flat strip as used in the thermopile for absolute measurements described on another page.

The thermopile as a photometer.-The requirement of this thermopile was to measure the blackening produced by star images on photographic plates. These star images were to be magnified and projected upon the thermopile receiver which was to be a disk $5 \mathrm{~mm}$ in diameter. The first design was constructed as shown in illustration No. 4 of Fig. 3. The receivers were semicircular disks (of tin $0.02 \mathrm{~mm}$ in thickness) to each of which were attached two thermoelements of bismuth (O. I mm) and silver. This series-parallel arrangement had a resistance of $1.2 \mathrm{ohms}$; and it required ro to $\mathrm{I} 2$ seconds to attain temperature equilibrium. Blackening the rear side of the receivers (in order to increase the emissivity) decreased this period only about I second. From other experiments it was concluded that this lag in attaining temperature equilibrium was owing to the slowness of heat conductivity from the extreme edges of the disk, distant from 2 to $2.5 \mathrm{~mm}$. Another thermopile was therefore constructed of exactly similar material, the only modification in the design being in the receiver, which was cut into four quadrants. One thermoelement was attached to the center of each quadrant, and the four elements joined in series as shown in illustrations No. 3 of Fig. 3, and in Fig. IB. The resistance was 2.4 ohms. This receiver, when exposed to radiation, attained temperature equilibrium in 5 seconds. Its radiation sensitivity was the highest of all the instruments constructed, being 39 per square millimeter area against 33 , which is the average value on the (arbitrary) scale of comparison. The area exposed is closely the same as that of the linear thermopiles, herein described, and 
its high sensitivity appears to be due to the fact that this area is comprised within a circle, which arrangement is the most efficient construction of a thermopile receiver.

$A$ thermoelement with a concentrating mirror.-The loss in efficiency in a large receiver is so great that in some kinds of work it may be more advantageous to use a small receiver and concentrate the radiations not intercepted by it upon the rear side of the receiver by means of a cylindrical mirror or by means of a cylindrical lens in front of the receiver. For example, the sensitivity of a receiver ( $16 \mathrm{~mm}$ long) which is used to measure the intensity of the radiation in a spectral line $\mathrm{I} \mathrm{mm}$ wide and $\mathrm{r} 6 \mathrm{~mm}$ long is only four times as great as that of a receiver $\mathrm{I} \mathrm{mm}$ long. If, for the measurement of the energy in a spectral line $16 \mathrm{~mm}$ long (and I $\mathrm{mm}$ wide), we place a concave cylindrical mirror at the rear of a receiver $\mathrm{I} \mathrm{mm}$ long (and $\mathrm{I} \mathrm{mm}$ wide), thus concentrating upon the receiver the energy not intercepted by it, we obtain the integrated effect of practically 16 receivers, each one of which is $\mathrm{I} \mathrm{mm}$ in length, and the galvanometer deflection will be about four times that observed when using a receiver $16 \mathrm{~mm}$ long. As shown in Fig. 6, one receiver gave a deflection of over $40 \mathrm{~cm}$, four receivers gave a deflection of $80 \mathrm{~cm}$, while $\mathrm{r} 8$ receivers gave a deflection of only $180 \mathrm{~cm}$ instead of about $700 \mathrm{~cm}$, which would have been obtained if the energy could have been concentrated upon the single receiver.

A hole in the center of the mirror permits adjusting the position of the thermopile in the spectrum (as described in Part VII of this paper). Using the finest material that can be manipulated (as described in the first caption of Part IX) in a highly exhausted inclosure, a single element and concentrating mirror should prove useful in some special kinds of radiometry, requiring the highest attainable sensitivity. For routine work, however, the regular linear thermopile in air is preferable.

Miscellaneous designs.-Under this heading may be mentioned designs of thermopiles which have already been constructed and tested; and also suggested improvements in others. For receivers in radiotelegraphy two forms were constructed which were kindly tested by Dr. L. W. Austin. The one consisted of strip of bolometer platinum I mm wide, about $15 \mathrm{~mm}$ long (resistance, $4 \mathrm{ohms}$ ), 
insulated between two thermopiles of bismuth and silver. The bismuth wires were $0.06 \mathrm{~mm}$ in diameter, pressed flat. The 0.03 $\mathrm{mm}$ silver wires were attached to these flat strips of bismuth, but no receivers were used. Either the platinum heater or the thermopile could be placed in the radio-receiving circuit. The device was reported to be very sensitive; but it was defective in that the platinum heater became warmed, causing a shift of the zero reading of the galvanometer. The second thermopile consisted of $0.06 \mathrm{~mm}$ bismuth wire and $0.03 \mathrm{~mm}$ silver wire, in which a mass of Wood's alloy was fused to the alternate junctures (and blackened), in order to change the heat capacity, so that the smaller junctures would become the more highly heated by the oscillating electric current passing through the instrument, and thus produce a thermoelectric current. The instrument was reported to be about as sensitive as a special tellurium couple in regular use. Since there did not appear to be a very marked gain in sensitivity as compared with other devices already in use, no further attempts were made in applying this thermopile in radiotelegraphy.

Another device, in the form of a thermoelectric generator capable of generating current by exposing it to sunlight deserves further attention experimentally. In it bismuth and copper, or copper and constantan thermoelements, with large receiving surfaces attached thereto may be used. The receiving surfaces are covered with asphaltum and the whole is inclosed in a glass covered box..$^{36}$ The coronal thermopile constructed by Callendar ${ }^{37}$ is an ingenious device consisting of bars of bismuth and antimony, with receiving surfaces in the form of copper rectangles. The receivers, which are arranged in the form of an annulus, are mounted in the eyepiece of a telescope and sighted at the moon during a solar eclipse. It appears possible to produce a quicker acting and perhaps a more sensitive instrument (radiometrically) by using a thermopile of bismuth silver with the tin receivers cut into the form of an annulus. For measuring the radiation from the solar corona Julius used a thermopile with a receiving disk 5 $\mathrm{mm}$ in diameter. Instead of the annulus, the disk receiver shown

\footnotetext{
${ }^{36}$ For a further description, see Letters Patent No. $₹$. 077 219, Oct. 28,1913 , which is dedicated to the public.

${ }^{37}$ Callendar: Proc. Roy. Soc., 77A, p. 8; 1905.
} 
in illustration No. 3 of Fig. 3 might be useful. If desired, the central portion could be covered with a smaller disk leaving an annulus of the required size.

As an illustration of the wide range of usefulness of the thermopile, it may be added that an instrument was constructed in which the receiver was in the form of a $U$-shaped trough, within or over which was suspended a wire through which a heavy electric current could be passed. The device is to be used as an ammeter, and its use was invoked to avoid distortion of the form of the electric wave used in a delicate magnetic test.

The thermogalvanometers on the market are said to be slow in their action. The fine bismuth wires now attainable, combined with a disk built up of quadrants as shown in No. 3 of Fig. 3, would produce a quick acting and perhaps a more sensitive instrument.

\section{SPECIFICATION OF THE RADIATION SENSITIVITY OF A THERMOPILE}

From the foregoing experiments it is evident that the radiation sensitivity of a thermopile can not always be defined in terms of the voltage produced. "Microvolts per microwatt" of radiant energy absorbed has but little meaning when used in connection with a Thomson galvanometer. This definition of sensitivity is, of course, useful when the measurements are made with a potentiometer or with a moving coil galvanometer. The ('Thomson) galvanometer deflection was found the same for two thermopiles having the same area exposed; the one having its 18 elements in series, the other having its 18 elements joined two in seriesparallel thus producing only half the voltage of the former. In the latter the heat capacity and emissivity was so far reduced that I microwatt of radiant energy produced 0.016 microvolt (or greater) per thermal junction. Since the thermoelectric power of bismuth silver is about 80 microvolts per degree, this is equivalent to a rise in temperature of about $20 \times 10^{-5}$ degree. In the herein described thermopile of bismuth alloy, the temperature rise was of the order of $26 \times 10^{-5}$ degree, while in the circular receiver, illustration No. 3 of Fig. 3 , the temperature rise was $46 \times$ $10^{-5}$ degree (or even higher according to the direct measurement of the voltage) per microwatt of radiant energy absorbed. While 
this description of the rise in temperature of the receiver shows the efficiency of these designs it is not so convenient as the timeworn specification of sensitivity in terms of the current sensitivity of the galvanometer, and a standard of radiation. However, instead of using the candle as a source of radiation, a calibrated incandescent lamp is recommended..$^{38}$ The current sensitivity of the galvanometer may be taken as $\mathrm{I} \mathrm{mm}$ deflection $=\mathrm{I} \times \mathrm{IO}^{-10}$ ampere. With this galvanometer sensitivity, I microwatt of radiant energy produces a deflection of $x$-centimeters per square millimeter of the receiver which is exposed to radiation. As a further check, the total area exposed and the scale distance (I meter) should also be specified.

The specification of the area exposed is desirable in view of the fact that the sensitivity is proportional to the square root of the total area exposed. This was thoroughly demonstrated on the large thermopile shown in illustration No. 2 of Fig. 3, the individual receivers of which were $\mathrm{I} .5$ by $3 \mathrm{~mm}\left(=4.5 \mathrm{~mm}^{2}\right)$ in area. Additional terminals were soldered to the small metal posts which support the individual elements, as described in the fore part of this paper. In this manner it was possible to determine the sensitivity of $4,6,8$, 10, or 18 junctions. The observed galvanometer deflections had to be corrected, of course, for variation in external resistance, by means of the data given in Fig. 2. The total area exposed was taken to be $4.5 \mathrm{~mm}^{2}$ times the number of junctions used. The galvanometer sensitivity and the standard of radiation were, of course, kept constant. The intensity of the radiation was $83 \times \mathrm{IO}^{-8}$ watt per $\mathrm{mm}^{2}$. The results obtained are given in Fig. 6, in which the ordinates are the observed galvanometer deflections in centimeters and the abscissae are the square roots of the areas exposed to radiation. The data are in exact agreement with the square root law as applied to a large receiving surface containing a plurality of thermojunctions. The data are in apparent disagreement with the results published in a previous paper ${ }^{39}$, which, however, relate to different conditions of the receiver. In the previous paper the experiments relate to a single thermoelement attached to a single receiver, the area of which was varied. It was then found, as was to be expected,

${ }^{38}$ This Bulletin, 11, p. 87, 1914; J. Franklin Inst., 176, p. 219; т913.

${ }^{39}$ This Bulletin, 9, p. 7; 1912. 
that there is an optimum size of receiver giving a sensitivity which is considerably ( 30 to 50 per cent) higher than the values obtained by applying the square root law, to observations on very small or very large receivers. From this it is evident that the best thermopile is obtained by using the most favorable area in the individual receivers.

In previous papers the sensitivities of the various types of radiometers were intercompared by considering the sensitivity proportional to the area. The sensitivity per square millimeter area exposed was therefore obtained by dividing the total deflection

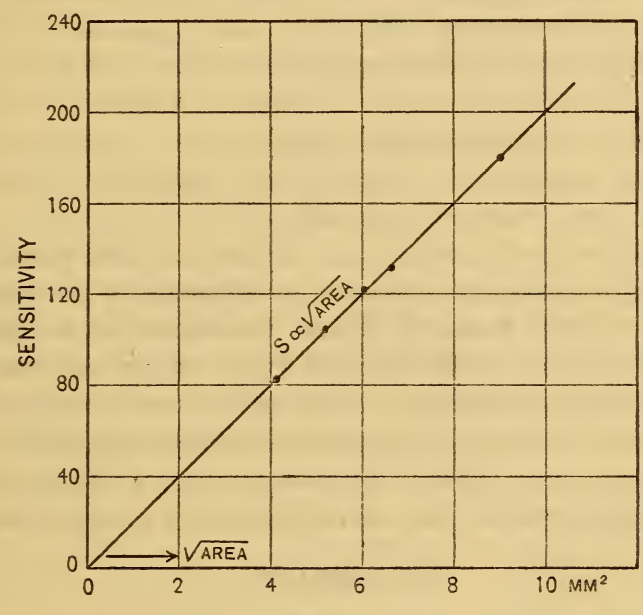

Fig. 6

(the radiometer was exposed to a standard candle) by the total area exposed. It was, of course, realized that the comparison was not a fair one; but it was in keeping with the accuracy of the data published by various experimenters. For bolometers and thermopiles the square root of the total area exposed should be used as the divisor. On this basis of comparison the average radiation sensitivity of the bismuth-silver thermopiles herein described was such that I microwatt of radiant energy produced a deflection of 2.9 to $3.0 \mathrm{~cm}$ per $\mathrm{mm}^{2}$ area exposed; scale at I meter; galvanometer sensitivity $\mathrm{i}=\mathrm{I} \times 1 \mathrm{O}^{-10}$ ampere. For example, $68976^{\circ}-14-12$ 
thermopile No. 36 (having two elements in series-parallel; resistance $\mathrm{I} .98 \mathrm{ohms}$; area exposed $31.2 \mathrm{~mm}^{2} ; \sqrt{\text { area }}=5.58$ ) produced a deflection of $97.5 \mathrm{~cm}$ for a galvanometer sensitivity of $i=4 . \mathrm{I} \times$ IO $^{-10}$ ampere. This deflection must be corrected by 9 per cent for inequality of external resistance (see Fig. 2) and by 1.5 per cent for the energy lost by reflection from the lampblack surface of the receiver. This corrected value (which is $107.7 \mathrm{~cm}$ ) when reduced to the value which would be observed with a galvanometer sensitivity of $\mathrm{i}=\mathrm{I} \times \mathrm{IO}^{-10}$ ampere, is equivalent to a deflection of about $445 \mathrm{~cm}$. The intensity of the radiation from the standard lamp being $88.9 \times$ 10- $^{8}$ watt per $\mathrm{mm}^{2}$, the total radiation falling upon the thermopile was (the total area exposed, $31.2 \times 88.9 \Rightarrow 27.7 \times 10^{-6}$ watt. Hence 1 microwatt of radiant energy produced a deflection of $(445 \div 27.7 \Rightarrow)$ I6.I cm and the sensitivity in centimeters deflection per $\mathrm{mm}^{2}$ of the total area exposed was $(\mathrm{I} 6 . \mathrm{I} \div 5.58 \Rightarrow) 2.89 \mathrm{~cm}$.

On the old basis of comparison, against a sperm candle which has a radiation intensity of about 30 microwatts per $\mathrm{mm}^{2}$, at a distance of $\mathrm{I}$ meter from the flame, the radiation sensitivity of these thermopiles is of the order of 87 to $90 \mathrm{~cm}$ per $\mathrm{mm}^{2}$ of the receiver exposed to radiation. Some of the special designs of bismuth and silver had a 5 to 20 per cent higher sensitivity. However, the values just quoted are conservative estimates of what may be attained without serious difficulties in construction.

\section{SUMMARY}

The novelty of the bismuth-silver thermopile ${ }^{40}$ as herein described consists of a receiver having a continuous surface and a definite area which permits calibration, for measurements in absolute measure.

Data are given on the relative sensitivities of thermopiles of bismuth silver, bismuth copper, bismuth alloys, and of bismuth iron. It is shown that the attainment of a high radiation sensitivity in a thermopile is mainly a question of neatness of construction (low heat capacity, conductivity, and emissivity) and that the thermoelectric power is of secondary importance. The radiation sensitivity of a thermopile of bismuth and silver is

\footnotetext{
${ }^{40}$ For further specifications, see Letters Patent, $108 \mathrm{x} 365$, Dec. $x 6$, 1913; dedicated to the public.
} 
almost (within ro per cent) as high as that of a thermopile of bismuth alloy having a 55 per cent higher thermoelectric power. These thermopiles have practically the same radiation sensitivity as a good air bolometer, and they are not so easily disturbed by air currents. They embody practically all the good qualities (except instantaneousness of action) of the bolometer.

Experiments are described on. the radiation sensitivity of a thermopile as a function of the area exposed, and of the thermoconductivity and emissivity; also as a function of the external and the internal resistance. It is shown that the external (galvanometer) resistance may be two or three times the internal resistance without decreasing the sensitivity more than 5 or ro per cent. After correcting for the difference in internal and external resistance, it was found that the radiation sensitivity of the thermopiles having all the elements in series was nearly as high as that of the thermopiles having the elements joined two in series-parallel.

A radiometer attachment to monochromatic illuminators is described, which enables the operator quickly and easily to determine the energy value of the stimulus. This is of importance to physiologists, psychologists, biologists and physicists who are investigating the effect of light stimuli upon matter.

A thermopile with a thin blackened strip of manganin or platinum in front of it, is described. This is a modification of the Ångström pyrheliometer, and it affords a quick and an accurate method for the measurement of radiant energy in absolute measure.

Special designs of thermopiles are described. They include stellar thermopiles; thermopiles for measuring nocturnal radiation; thermopiles to be used as photometers; thermopiles with the receivers in the form of $U$-shaped troughs for physiological problems; and miscellaneous thermopiles for measuring small electric currents in radiotelegraphy, etc.

The results herein described are part of the experience gained in the construction of various designs and modifications of thermopiles to suit various problems which promised solution by radiometric methods. It has involved the construction of more than rooo thermal elements and (since each element consists of 5 
pieces) the handling of about 5000 or more pieces of material The failures are of course not described. After several days of work on a new design the resulting thermopiles sometimes proved less valuable than the frame upon which it was mounted. It was therefore promptly cut from the frame, to be replaced after four hours further work with a similar design having the properties herein described. This was the experience with the very first thermopile (of bismuth iron) which led to the construction of the first bismuth-silver thermopile; and it was the experience of the first series-parallel arrangement of the elements. The data are given with the hope that they may be of assistance to others in widening the field of usefulness of this form of radiometer.

In conclusion it is pertinent to add that the thermopile and the bolometer recognize no sharp dividing line of "ultra-violet," "visible," and "infra-red" as marked by the eye and the selenium cell. Using a suitable spectrometer it is just as easy to observe in the ultra-violet as in the extreme infra-red. Using the spark spectra of $\mathrm{Al}, \mathrm{Mg}, \mathrm{Cd}$, and $\mathrm{Zn}$; the acetylene flame; the nitrogenfilled tungsten lamp; or the Nernst glower, much valuable work may be done throughout the spectrum, extending to $0.25 \mu$ or to even shorter wave lengths in the ultra-violet. The thermopile therefore deserves a fair trial as compared with the spectrophotometer, which is limited in range, and as compared with photographic photometry with its questionable time exposure, fogging of plates in development, and standardization of plates, which vary in sensitivity in different parts of the spectrum.

Wasmington, March 20, 1914. 


\section{APPENDIX \\ NOTE 1.-GALVANOMETER MIRRORS}

The idea seems to prevail that thin glass or quartz mirrors with plane surfaces can not be made plane or kept plane in mounting them; and hence selected microscope cover glass will be just as satisfactory. This is entirely erroneous, for the surface of the thin cover glass is extremely uneven. On the other hand the optically worked material of the same thickness as the cover glass is free from unevenness over its surface. In mounting such a thin mirror the surface may become curved (this is also true of the cover glass), but it will have a definite curvature without the minor undulations to be found in the cover glass.

Having had such optically worked mirrors in successful use for several years, it is desirable to call attention to their superior qualities, as well as the manner of construction. The first step in producing these thin mirrors is to grind a flat surface upon a thick ( 5 to $8 \mathrm{~mm}$ ) plate of glass which acts as a holder. The sample which is to be used for mirrors is also ground flat, and polished on one side, which is then cemented to the glass holder. The other side of the sample is then ground flat. The sample may be wedge shaped but that is unimportant. Having ground the sample to the desired thickness (say $0.08 \mathrm{~mm}$ to 0.15 ) the surface is polished, and it may be rendered optically plane to one-fourth of a wave length of light. On removing this thin plate from the holder it will be found that the surfaces are plane to one-fourth (to one-half) of a wave length of light. This plate is then platinized by cathode disintegration and cut into strips of the desired dimensions by means of a crystal of carborundum. Mirrors produced by cathode disintegration of antimony are white and usually more highly reflecting, which suggests the use of this metal, since platinum is inclined to produce brownish colored mirrors. The mirror is attached to the galvanometer suspension by a mere trace of adhesive material, e. g., universal wax or tallow, and there is no tendency to distort the mirror which happens when it is attached with shellac. The weight of such a mirror, 2.5 by I.5 by $0.1 \mathrm{~mm}$ is about $x .5 \mathrm{mg}$.

NOTE 2.-VACUUM GALVANOMETERS

The current sensitivity of a needle galvanometer is usually stated to be proportional to the square of the period; and it is also proportional, to the square root of the resistance of the coils. ${ }^{41}$

41 Kohlrausch Lehrbuch Praktischen Physik. Jaeger., Ann, der Phys. (4), 21, p. 53; 1906. 
This may have been true of the older forms of galvanometers with their ponderous magnet systems, but the sensitivity of the galvanometers of recent construction, with their light suspended systems, is not proportional to the square of the period. In a paper by Abbott ${ }^{42}$ attention was called to this fact. With reference to the suspensions used by him no definite statement was made as to their behavior other than that "the deflection is not even approximately proportional to the square of the period." However, by exhausting the air to $0.2 \mathrm{~mm}$ pressure, he found that "the deflection was proportional to the square of the time of swing up to a time of single swing of 5.5 seconds." If this refers to the 16 -coil galvanometer, it may explain the discrepancy between his observation and those by the writer.

In a previous paper ${ }^{43}$ data were published showing that the sensitivity of the 4-coil galvanometers used by the writer is proportional to the period. It was therefore of interest to try one of these galvanometers in vacuo. For this purpose the four $26-\mathrm{ohm}$ coils (mentioned on a previous page), mounted in Swedish iron shields, was used. A glass bell jar was placed over it and the air was exhausted to less than o.I $\mathrm{mm}$.

The coils were wound in 5 layers of about 5 ohms each of Nos. 40, $38,36,34$, and $28, \mathrm{~B}$. S. gauge wire covered with a single layer of white silk. The outer diameter was $33 \mathrm{~mm}$. The magnet suspension consisted of two groups of magnets, having 4 needles in each group. These needles were from I.2 to $1.5 \mathrm{~mm}$ long (longer than usual) and the total weight was about $6 \mathrm{mg}$, the mirror weighing $1.5 \mathrm{mg}$.

The sensitivity test in air showed that the law of current sensitivity with square root of the resistance held for the series-parallel (26 ohms) and all in parallel $(6.5 \mathrm{ohms})$, but fell below the required value by 8 per cent for all coils in series (ro4 ohms). This galvanometer was not constructed with the expectation of surpassing others on hand. The suspension and especially the mirror was heavier than is usually employed. The main interest in this test was its behavior in vacuum, to be described.

The results of this test show (see Fig. 7, the circles represent an entirely new set up of the instrument) that for a single swing greater than two seconds, the sensitivity, in air, is proportional to the time of swing, while in vacuum the sensitivity increased somewhat more rapidly than the time of swing. The actual gain in sensitivity in a vacuum was about roo per cent for a swing of two seconds, and only about 25 per cent when the swing was greater than four seconds. In air, with a single swing of four 
seconds, the deflection was completely damped; and with the air exhausted the needle had one turning point of small amplitude before coming to rest. For a time of single swing of two seconds the needle had two turning points before coming to rest, but in air the amplitude of swing was much less. The damping is evidently almost entirely magnetic, but it is not sufficient to be affected by the external resistance. In fact the writer has had but

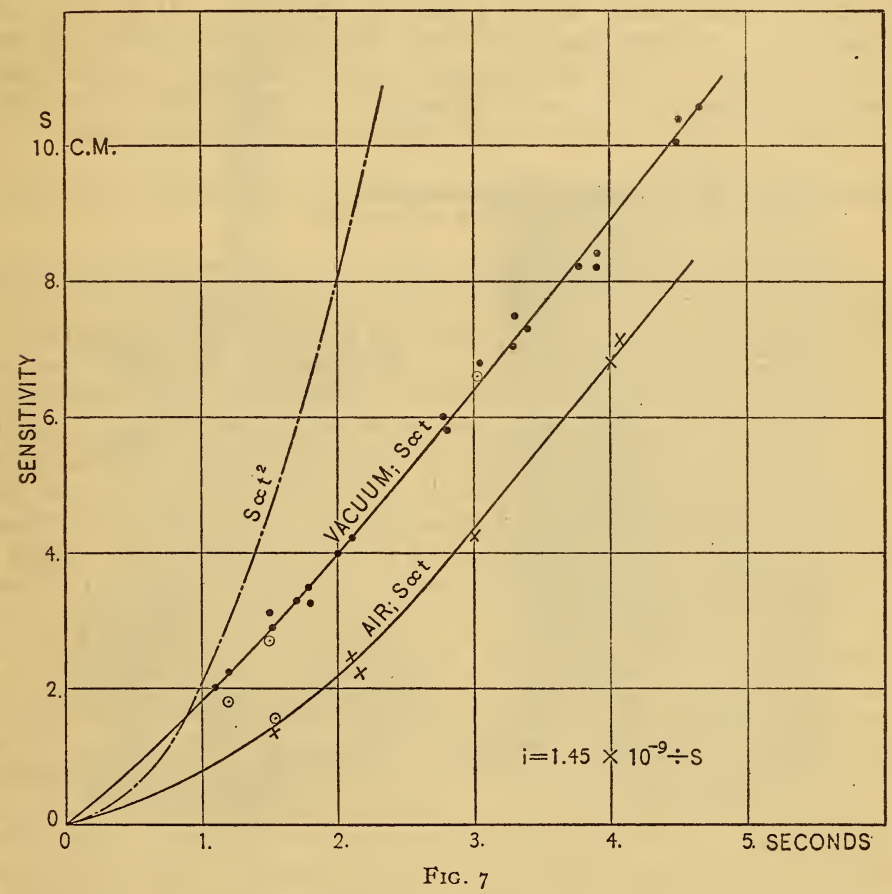

one Thomson galvanometer in which the damping was affected by the external resistance in circuit. The magnets in the present galvanometer suspension were made from fine piano wire, hammered flat and hardened "glass hard." From the results obtained it appears that one must test the galvanometer before being certain that there will be a marked gain by placing it in an evacuated inclosure. 
The iron clad galvanometer previously described ${ }^{44}$ has been found to possess such excellent magnetic shielding that a more elaborate one was constructed. It is shown in Fig. 8. The four coils are embedded in blocks of Swedish iron, each block being 2.5 by 5 by $9 \mathrm{~cm}$. Theoretically a circular form would be better because it is more symmetrical. A lamellated shield is shown in the right-hand side of the illustration. It consists of about i 5 turns of transformer iron $0.4 \mathrm{~mm}$ in thickness. It is of course unnecessary to have the slots cut in the shield, especially the one at the bottom. This combination provides almost as good magnetic shielding as the more elaborate soft pipe outfit previously described. There are of course additional shields provided.

NOTE 3.-THE MOST EFFICIENT COMBINATION OF THERMOPILE AND GALVANOMETER RESISTANCE

In the foregoing tests of the sensitivity of thermopiles the same galvanometer was used. After making a correction for loss in efficiency due to inequality of internal and external resistance, it was found that the sensitivity of the type of thermopile having all the elements in series (resistance about $8 \mathrm{ohms}$ ) was practically the same as that of the type of thermopile having two elements joined in series-parallel (resistance about $2 \mathrm{ohms}$ ). Hence, aside from the fact that the series-parallel arrangement may be the quicker in attaining temperature equilibrium, there is no preference in the manner of construction of the thermopile when using a Thomson galvanometer. However, in the fulfillment of the condition of equality of internal and external resistance, a question remaining unanswered is the most efficient resistance of galvanometer coils to be used with the thermopile, i. e., whether a galvanometer made of coils of high resistance (say 4 coils each having a resistance of $32 \mathrm{ohms}$, and all in parallel giving $8 \mathrm{ohms}$ ) should be used with the thermopile of $8 \mathrm{ohms}$, or whether a galvanometer having coils of low resistance (4 coils in parallel, each coil having a resistance of 8 ohms) should be used with this same thermopile, having its elements joined two in series-parallel, and thus having a resistance of about 2 ohms. Another combination would be four coils of $2 \mathrm{ohms}$ each joined in series-parallel. Theoretically, the force exerted by a coil varies nearly proportionally to the square root of the resistance. While this relation does not hold for large resistances, the results ${ }^{45}$ shown in Fig. 9, indicate that a galvanometer having four coils of 32 ohms each (and giving 8 ohms when joined in parallel) is 6 per cent less sensitive than

14 This Bulletin, 9, p. 6r; 1912 (see Fig. 17 ).

45 This curve is computed from data published by Abbott (Annals Astrophys. Obs., 1, p. 250) on the force exerted by galvanometer coils of different resistances. 


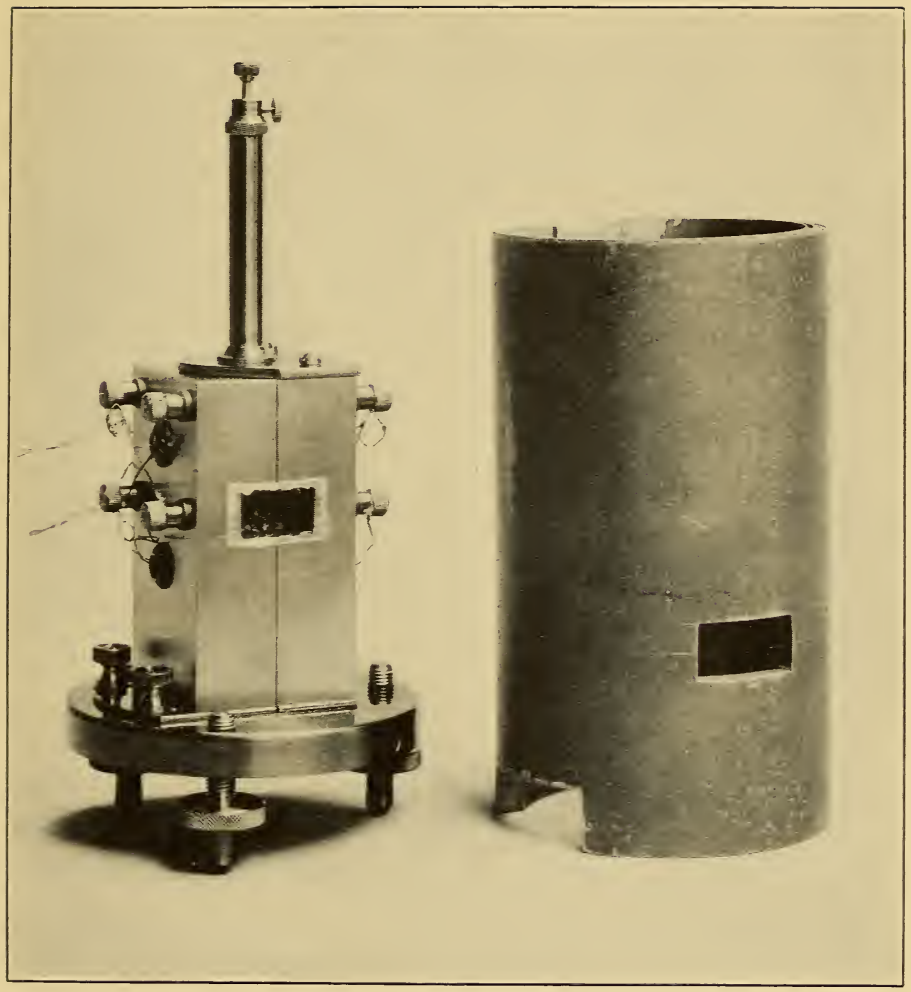

Fig. 8.-Ironclad galvanometer 
a galvanometer having four coils of 8 ohms each, or 2 ohms when all the coils are joined in parallel. This is not a very marked difference in sensitivity, and as with the various thermopiles constructed, the writer's experience is that the sensitivity attainable in a galvanometer is dependent mainly upon the construction of the suspended system.

The radiation sensitivity of a bismuth-silver thermopile with I6 elements joined two in series-parallel and having a resistance of r.84 ohms, was tested when connected with galvanometer coils differing widely in resistance. The first galvanometer which was used was constructed of coils having a resistance of 2 I ohms (B. S. No. 40, 34, and 28 wire), and as used, with all the coils in parallel, had a resistance of $5.09 \mathrm{ohms}$. From the experiments on external and internal resistance, a correction of about Io per cent had to be applied to the deflections when using this thermopile. The second galvanometer was constructed of four coils, each having a resistance of $7.6 \mathrm{ohms}$ (B. S. No. 38,30 , and 26 wire), and as used had a resistance of $\mathrm{I} .92$ ohms. The computed normal current sensitivity ${ }^{46}$ appeared to be very closely the same for these two instruments. These two galvanometers

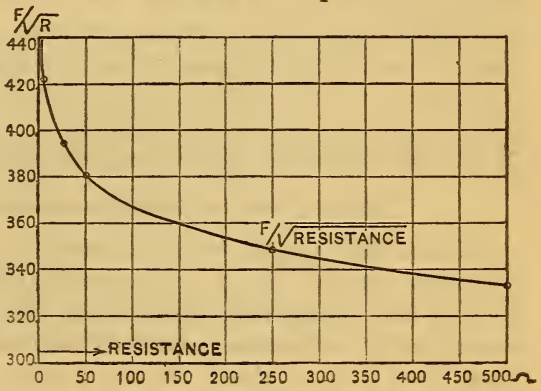

FIG. 9 were used with the same thermopile of 1.9 ohms, corrections being made for inequality of external resistance when using the one galvanometer. The thermopile was exposed to a standard of radiation. The deflections were considerably larger (ro to 15 per cent) when using the low-resistance galvanometer. The efficiency (in galvanometer deflections) of the low-resistance combination appeared to be Io to I 5 per cent higher than was to be expected from the high-resistance combination. In other words, the low-resistance thermopile (elements joined in series-parallel) and an equally

46 The normal sensitivity is usually defined to be the deflection produced at a distance of $x \mathrm{~m}$ when a current of $\mathrm{I} \times \mathrm{ro}^{-6}$ amperes is passed through the galvanometer, the time of complete swing being brought up to ro seconds and the resistance being reduced to I ohm. For this purpose the sensitivity is usually taken to be proportional to the square of the period and proportional to the square root of the resistance. The procedure is misleading, especially as regards the period. In some of the galvanometers described by various experimenters, the mirror is so small that the scale can nut be placed at a much greater distance than I $\mathrm{m}$. Moreover, the coils ( $I_{5}$ to $20 \mathrm{~mm}$ in diameter) do not give a large range of proportionality of deflections with current. In the present galvanometers the coils are $33 \mathrm{~mm}$ in diameter; they have a large deflections with current. In the present galvanometers the coils are 33 mm in diameter; they have a large ening the scale distance of $3 \mathrm{~m}$. The sensitivity is proportional to the period, at least for periods greater than I second, which is the usual condition of operation. 
low-resistance Thomson galvanometer seem preferable to the highresistance (elements all in series) thermopile and its auxiliary galvanometer.

On the other hand, if the thermopile is used with a d'Arsonal galvanometer, conditions are different, owing to the large (external) critical damping resistance in this instrument. As already mentioned, it is desirable to use a great many thermoelements joined all in series when the thermopile is to be used with a moving coil galvanometer. In this manner the greater part of the critical damping resistance of the galvanometer may be replaced by the resistance of the thermopile. For example, a critical damping resistance of Io to $12 \mathrm{ohms}$ may easily be supplied by a thermopile of 20 to 24 thermoelements, which are joined in series. The emf produced will be twice that of the elements joined two in series-parallel, and the galvanometer deflection of the all-in-series arrangement should be twice that of the two-in-series-parallel arrangement. This, of course, is just the opposite to the results with the Thomson galvanometer. The latter, however, is the more sensitive instrument, and on a single swing of 2 to 3 seconds a current sensitivity of $i=3$ by $\mathrm{ro}^{-10}$ amperes is easily attained.

\section{NOTE 4.-TEST OF STELLAR THERMOELEMENTS ON STARS}

While this paper was in press it was possible, through the courtesy of Dr. W. W. Campbell, Director of Lick Observatory, to test the sensitivity of some of the stellar thermoelements, just described in connection with the Crossley reflector. For this purpose from two to three elements were mounted in evacuated glass receptacles, as shown in Fig. Io, which contains two elements. Instead of the fiber mounting shown in Fig. 3, No. 4, the elements were attached to platinum lead wires, which were sealed into a glass tube. To the platinum wires were attached copper wires, No. I and No. 2, shown in Fig. Io. The glass tube containing the platinum wires was sealed into a thick piece of plate glass, $G$, by means of Khotinsky cement, $\mathrm{K}$. The quartz-glass tube, containing the metallic calcium, $\mathrm{Ca}$, was likewise attached permanently with this cement, $K$. The main portion of this glass receptacle consisted of a single piece of glass, $\mathrm{E}$, with a projecting glass tube containing potential terminals, $\mathrm{P}$, for testing the evacuation. A fluorite window, $\mathrm{F}$, admitted the stellar radiations into this glass vessel, and upon the thermoelements, which are supported by the platinum lead wires to be seen through the glass vessel $\mathrm{E}$. The rear window of glass $\mathrm{G}$ was attached by means of stopcock grease, covered with Chatterton wax.

This peculiar form of construction was necessary in order to be able to use the device when attached to the plate holder, in the 


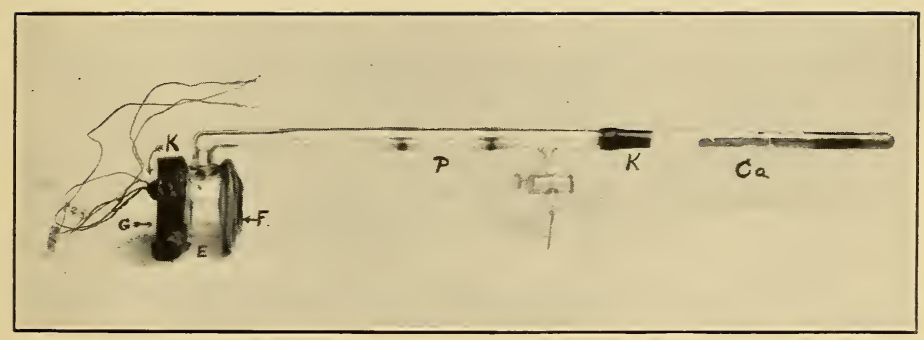

Fig. IO 
focus of the telescope mirror. The star image and the receivers of the thermoelement are viewed from the side of the telescope tube by means of a right-angled prism and a lens mounted close to the glass plate G. It was therefore necessary to design the radiometric attachment. so that all projecting parts extended downward in the direction of the reflecting mirror. This mirror has a focal length of $534 \mathrm{~cm}$ and a clear aperture of $92 \mathrm{~cm}$, affording a ratio of aperture to focal length of $\mathrm{I}$ to 5.8 .

Two receptacles, as shown in Fig. Io, were prepared for the test. The one (No. 7) contained an element of bismuth-platinum and an element of bismuth-bismuth tin alloy ( 5 per cent tin). The second receptacle (No. 6) contained an element of bismuthbismuth and tin alloy, and two elements of bismuth-platinum. In one of the latter elements the bismuth was folded so that the two receivers were side by side, in order to easily expose the receivers alternately to the star image. The two elements in receptacle No. 7 were selected from the best found in previous tests and were remounted. The three elements in receptacle No. 6 were mounted just before leaving for Mount Hamilton, and there was no time for the preliminary radiation sensitivity tests.

These two receptacles were evacuated, the stopcocks were secured with Chatterton compound, and the vacuum was thereafter maintained by warming the metallic calcium, Ca, Fig. Io, by means of a small alcohol blast lamp. This outfit was taken to Mount Hamilton, Cal., a distance of about 3200 miles, without serious mishap (one element in No. 6 was broken in climbing the mountain), and the calcium was occasionally heated with the alcohol blast lamp to remove any vapors that may have been evolved. Some time after arrival on Mount Hamilton one of the receptacles began to leak a little. This was remedied by applying a coat of shellac to the ground joints. A vacuum pump was taken along for security against serious accidents, but it was never unpacked. From this it is evident that, equipped with a number of evacuated receptacles containing thermoelements, one can go to the remotest regions to make radiometric measurements without being obliged to carry a heavy pump. This is one of the principal achievements in connection with the work.

In the radiation sensitivity tests on stars it was found, as it had been previously observed in the tests on artificial stars, that there was but little difference in the radiation sensitivity of bismuthplatinum thermoelements as compared with the elements of bismuth-bismuth and tin alloy which had a 50 per cent greater thermoelectric power. The pair of elements used in No. 7 were selected from previous tests, and, as used in the reflector, the element of bismuth-bismuth and tin alloy was only about ro per cent more 
sensitive than the element of bismuth-platinum. In the latter the receivers were tin globules pressed flat, as already described. In the former the receivers were of Wood's alloy (used as a solder), which was pressed into a thin disk between thin plates of mica, the pressure being applied when the solder was in a molten state.

The behavior of the bismuth-bismuth tin alloy element in receptacle No. 6 was unusual in that one receiver (of Wood's alloy pressed flat when in a molten state) was about 40 per cent more sensitive than the other. The least sensitive receiver attached to this element was about ro per cent less sensitive than the receivers joined to the element of bismuth-platinum. In the latter the two receivers had practically the same radiation sensitively.

It is beyond the scope of the present paper to include the results obtained in measuring the radiation from stars. These radiation measurements are quantitative on stars down to the 5.3 magnitude, while good qualitative measurements were made on stars down to the 6.6 magnitude. In all, I I 2 celestial objects were measured, including Saturn's rings, the dark and the bright belts of Jupiter (also a pair of his moons which happened to be close together), and a planetary nebula, which, however, gave no positive deflections. In this preliminary survey it was shown that red stars are emitting radiation at a far more rapid rate than blue stars of the same photometric magnitude. These observations were substantiated by using an absorption cell of water $\mathrm{I} \mathrm{cm}$ in thickness, which absorbs all the infra-red beyond I.4 $\mu$. This test eliminated the question of the size and the distance of the star. It showed that comparing stars of the same photometric brightness, the red stars emit from 2 to 3 times as much infra-red radiation as do the yellow and the blue stars. This shows why it is that a red star causes a galvanometer deflection which is 2 to 3 times that produced by a blue star of the same photometric brightness.

Before going to Mount Hamilton it was the intention to use certain stars as standards of radiation in testing the radiation sensitivity of the thermocouples. After several nights of observation it was found that a slight variation in humidity caused a great variation in the total amount of radiation from the standard star, so that any possible variation in the radiation sensitivity of the thermocouple was negligible in making the measurements. In other words, the thermocouple was used to observe the variation of atmospheric transparency for stellar radiations. This variation in transparency was most marked for red stars, as was to be expected from the tests with the water cell. 
Time did not permit the construction and testing of stellar bolometers, as had been planned, to compare with the stellar thermopiles. However, from tests made in the laboratory and from the tests of vacuum bolometers by Buchwald, ${ }^{47}$ it does not appear that the radiation sensitivity of a vacuum bolometer will be much higher than the radiation sensitivity of the hereindescribed vacuum thermoelements. Buchwald's experiments show that the radiation sensitivity of the bolometer was increased from 4 to 5 times when the air was evacuated to a pressure of $0.00 \mathrm{Imm}$, which is the same increase in sensitivity as observed in the herein-described thermoelements. The thermoelement is no doubt the least affected by wind and by temperature variations, so that, even though it may be slightly less sensitive than the bolometer, it will be the steadier in its behavior when connected with the auxiliary galvanometer, and it will be possible to read smaller deflections. On several nights observations were made on stars with a wind blowing upon the apparatus at a velocity of over 20 miles per hour, which gives some idea of the steadiness of the stellar thermocouple.

It is of interest to record that the galvanometer used in these tests was the ironclad instrument shown in Fig. 8. It stood upon the south pier which forms one of the two supports of the polar axis of the reflector. The galvanometer was therefore very close to the heavy iron telescope tube. In spite of this fact, the rotation of the telescope tube affected the galvanometer only when the reflector was directed upon stars situated low on the northern horizon, which brought the lower end of the telescope tube within I meter from the galvanometer.

It is of interest to record also that aside from its excellent magnetic shielding the galvanometer sensitivity was not greater than that ordinarily used in the Bureau of Standards, viz, $i=1.5$ $\times 10^{-10}$ ampere.

NOTE 5,-THE MANNTENANCE OF HIGH VACUA BY MEANS OF METALLIC CALCIOM

It is a well-known fact that metallic calcium when heated has the property of combining with all atmospheric gases except argon. The application of this property of metallic calcium as an evacuator has been suggested as a result of the researches made by Moissan ${ }^{49}$ and by Arndt. ${ }^{49}$ Experiments on the production of high vacua by means of metallic calcium have been made by

47 Buchwaid: Ann. der Phys. (4), 35, p. 928, I9zo.

49 Moissan: Compt. Rend., 127. p. 29, 497, 584; 129, p. I757, I89S.

4 Arndt: Ber. d. Deutsch. Chem. Gessell., 37, p. 4733; rga4. 
Soddy. ${ }^{50}$ A summary of the results of these experiments may be found in Baly's Spectroscopy. ${ }^{51}$

In preparing the receptacles for the thermoelements shown in Fig. Io the main difficulty experienced was in producing an airtight container. This required so much time that, starting with the general information that calcium is useful in producing a vacuum, the application of this material for maintaining a vacuum in the present apparatus was perfected independently of previous work. In fact, the paper by Soddy was not consulted until after arrival on Mount Hamilton. This no doubt was a fortunate procedure, for some of the results obtained in the use of calcium as an evacuator seem to be at variance with previous experiments and also at variance with the prevailing notion that calcium very readily attacks quartz. For example, it was found that a lightwalled, quartz-glass tube could be used to contain the metallic calcium, as shown in Fig. ro. This tube can be heated to a low red heat without danger of cracking, or collapsing when evacuated. At this temperature the metallic calcium unites readily with the residual gases, without attacking the quartz-glass tube. If heated to a bright red temperature, the hydrides and nitrides of calcium are dissociated and gases are evolved. On cooling these gases again combine, and, on admitting a small amount of air through the stopcock, it was found that nitrogen, etc., continued to combine with the calcium until the temperature had fallen to about $300^{\circ}$. If the calcium is heated to a very bright red then it, of course, combines chemically with the quartz glass. However, by evacuating the air to a pressure of about $0.1 \mathrm{~mm}$ there is no necessity for heating the calcium to a higher temperature than that indicated by the red glow of the quartz-glass tube.

Before closing the container permanently it was found best to evacuate the air to a low pressure and heat the calcium to a bright red, which dissociates the hydrides, etc. The pumping is continued, and air is admitted repeatedly to assist in clearing the water vapor from the walls of the receptacle.

Some of the air admitted combines, of course, with the hot calcium, but that it not detrimental. The quartz-glass tube may become black from the vaporized calcium, as shown in Fig. Io (this is container No. 7, described in Note 4), but that seems to be beneficial rather than detrimental. In fact, calcium in container No: 6 (see Note 4) was not given this severe preliminary heating before detaching it from the pump, and the best vacuum was produced only after some of the calcium had been vaporized by a subsequent heating to a bright red. The black deposit on the walls of the quartz-glass tube is easily removed by means of soap and water. 
As mentioned in Note 4, what vapors, if any, were given off by the stopcock grease and the Khotinsky cement were removed by heating the calcium by means of an alcohol blast lamp, which was the most convenient method of heating on a mountain. A small electric heater surrounding the quartz tube might be provided in a permanent laboratory equipment. Now that the device has been shown to be useful, it is possible to eliminate the stopcock, thus removing one source of possible leaking. However, the stopcock is the most useful part of the apparatus in case of breakage, and it is not detrimental to retain it. The stopcock grease used was a haphazard combination of beeswax and mutton tallow (which was too hard for frequent turning of the stopcock), to which had been added a combination of rubber dissolved in vaseline. The latter when used alone was too soft to withstand the pressure upon the stopcock. The whole was heated in vacuo to remove the air, and happened to be an excellent mixture. The Chatterton compound gave off vapors, and hence was used only as an outside cover because of its pliability when subjected to slow changes by expansion and contraction. As mentioned in Note 4 , there seemed to be no leaking of air, and the vapors released from within were easily removed. If the receptacles had leaked, all the constituents of the air could have been removed, except argon, of which there would have been an accumulation, which eventually would have been sufficient to reduce the radiation sensitivity of the thermoelements. Judging from the faint bluish discharge in container No. 6, when operated on an induction coil, there was present a small amount of argon, introduced by a temporary leak, as already mentioned.

As to the actual degree of evacuation attained, no exact measurements were made. It was found that after warming the calcium the discharge from a ro,ooo-volt transformer could not be passed through the tube. At Mount Hamilton the tests were made with a small induction coil operated by two "dry batteries." In this test the discharge would pass through the 5 -cm air space between the electrodes $\mathrm{P}$, Fig. Io, in preference to passing through the evacuated space within the tube. With reference to the efficiency of the device it may be added that this evacuator employing calcium to maintain a vacuum was found superior to the carbon electrode evacuator described by Pfund. ${ }^{52}$ In the latter it was found that if the discharge was too vigorous gases would be expelled, which could be removed only by pumping or by heating the calcium evacuator which was tested at the same time. On the other hand, if the calcium be overheated, thus dissociating the hydrides, etc., the gases are again combined on cooling. 